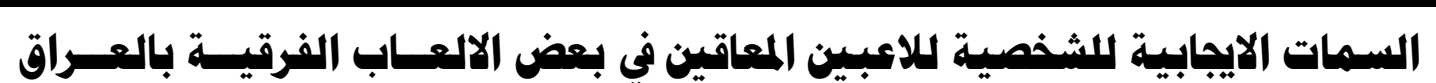 \\ أ.د مؤيد عبد الرزلق حسو dr.moayed.hasso@gmail.com

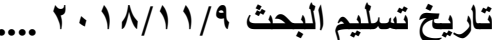

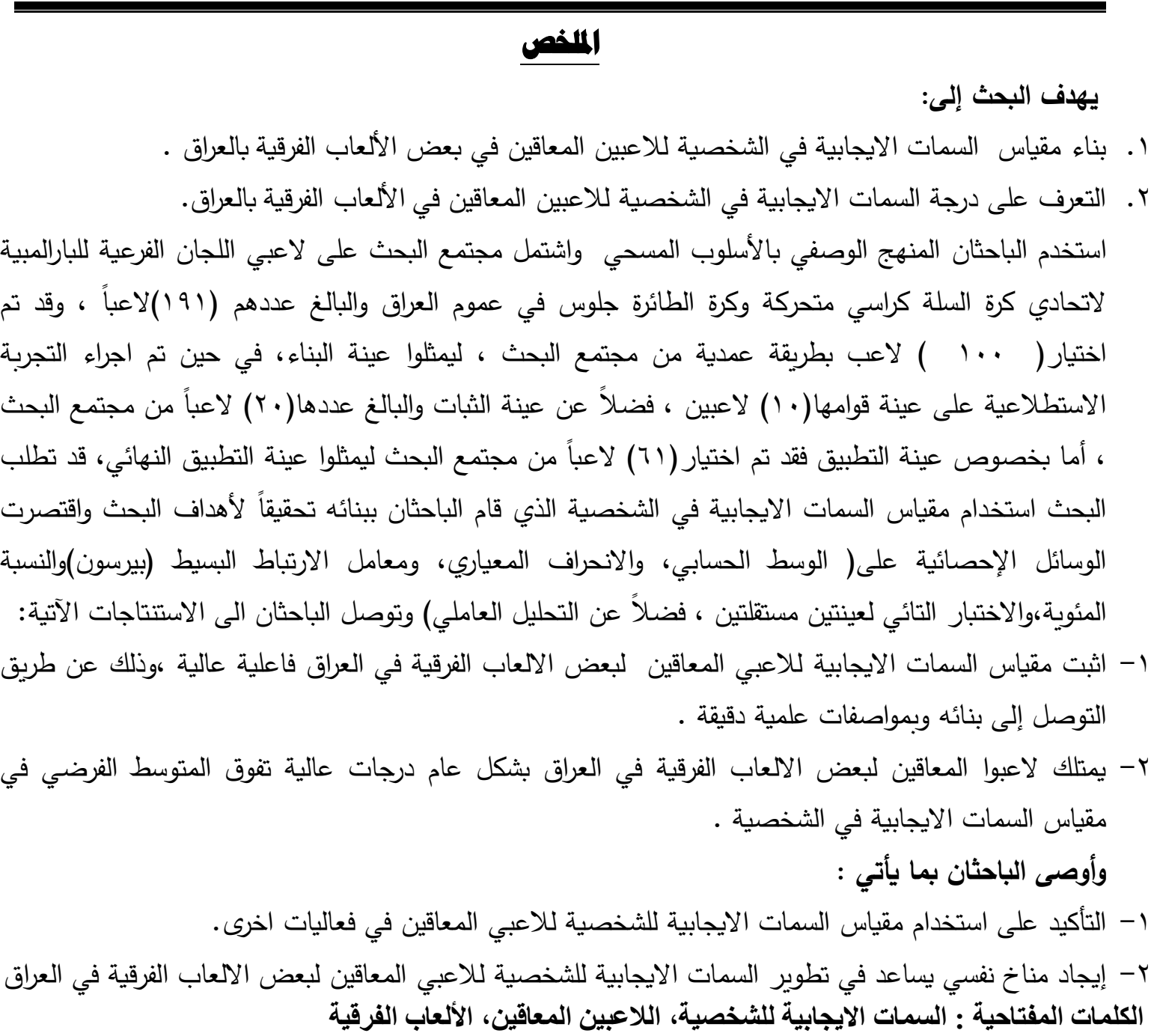

\section{Positive personality traits for players disabled In some Iraqi team games}

Prof. Dr. Moayed Abdul-Razaq Hassoｄr.moayed.hasso@gmail.com

\section{Ebtehal Mohammed Yousef}

The current research has aimed into identifying the following:

1. Constructing a scale for the Positive personality traits for players disabled In Iraqi team games

2. Identifying the differences in the Positive personality traits for players disabled In Iraqi team games.

The researchers used the descriptive method in the survey style, the research community included members of the Paralympic sub-committees of the wheelchair basketball federation and, volleyball - sitting in Iraq and their number(191) had been selected(100) Player of the search community to represent the construction sample, While the stability sample conducted on (20) players, and As for the application sample, 61 players from the research community were selected to represent the final 


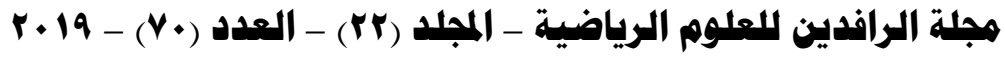 \\ السمات الايجابية للثخصية للاعبين المعاقين في بعض الالعاب الفرقية بالعراق}

application sample. So, the research has required using the scale of the Positive personality traits Which the researchers construct .

The researchers require $d$ in constructing the scale of Positive personality traits, The statistical means have consisted of mathematical mean, standard deviation, simple correlation coefficient (Pearson), percentages, and t test for two independent samples and factor analysis ., the researchers concluded the following:

1. The scale Positive personality traits for players disabled in Iraq $\mathrm{f}$ has proved to be very effective by constructing .it with precise scientific specifications.

2 .The players disabled in some Iraqi of the games team in generally have higher scores than the hypothesis average in the positive character traits scale.

the researchers had recommended the following:

1. Emphasis on using the scale for the Positive personality traits for disability players In some Iraqi team games.,

2. Emphasis on creating psychological Factors that helps in developing the positive features for disability players In some Iraqi team games.

Keywords: positive personality traits, handicapped players, team games

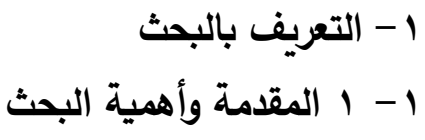

ظهر في السنوات الاخيرة اهتمام العلماء والباحثين في مجال علم النفس باتجاه علم النفس الايجابي بوصفه تيار حديث في علم النفس انطلق على يد Martin Seligman رئيس الرابطة الأميركية لعلم النفس، ويركز على أوجه القوة في الإنسان بدلا من أوجه القصور وتدور موضوعاته على المستوى الذاتي حول الخبرة الذاتية الإيجابية،وهي الرفاهية الثخصية، والسعادة ، والتدفق، والسرور والمتع الحسية، والمعارف التفاؤل،والأمل

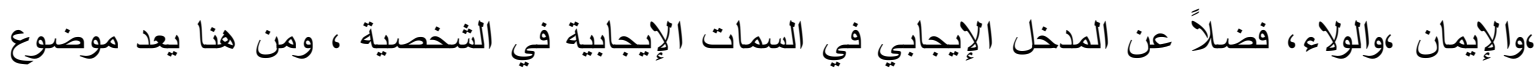
السمات الايجابية في الثخصية إحدى أهم المواضيع الحيوية التي تلاقي اهتماماً كبيراً في مجال علم النفس الايجابي والرياضي،إذ يتطلب فهم طبيعة العامل النفسي المصاحب للأداء الرياضي معرفة التركيبة السيكولوجية، والتي اهمها خصائص السمات الايجابية ، اذ توكد المصادر العلمية بان معظم العلماء يثيرون إلى أن السمات الايجابية في الثخصية هي (التفاؤلوالامل،والصلابة النفسية،والمرونة النفسية،وتقدير الذات،والطلاقة النفسية،وفاعلية الذات،والارادة،والمثابرةوغيرها)التي تعد بمثابة دعائم مفهوم علم النفس النس الايجابي، اذ ان هذه السمات تعمل كعامل وقائي ضد التهديدات التي يتعرض لها الفرد وتزود أيضاً الفرد بالطاقة اللازمة لمواجهة الحياة بفاعلية،وفي المقابل فإن الحياة الرياضية التي يعيشها الرياضيون ولاسيما الرياضيون المعاقون،تسم بالعديد من المتطلبات التي تفرضها طبيعة المنافسات الرياضية،كما ان تحقيق الانجازات الرياضية الكبيرة في رياضة المعاقين، تعتمد بثكل كبير السمات إيجابية لشخصية التي بوساطتها يستطيع الرياضيين مواجهة أقصى انواع الضغوط سواء البدنية منها ام النفسية أو الاجتماعية،ومن هنا تكمن أهمية البحث والحاجة إليه من خلال اطلاع الباحثان على الأطر والدراسات النظرية استدلا على ندرة الأبحاث التي تكيف الإسهامات السيكولوجية التي أسس لها علماء النفس الإيجابي، ولا سيما ما يرتبط منها بمفهوم

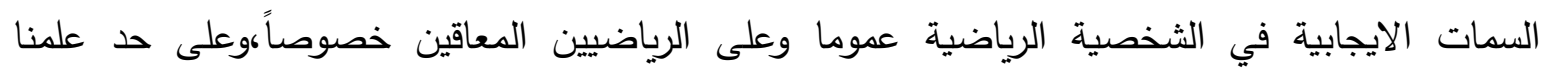
واطلاعنا على الدراسات السابقة فإننا لم نجد دراسات علمية حاولت الاهتمام بالسمات الايجابية في الثخصية للاعبين المعاقين وحصراً في الألعاب الفرقية بالعراق. 
تعاني رياضة المعاقين في المجتمع الرياضي ما تعانيه من اغفال مقارنة بالرياضيين الأسوياء،إذ تحتاج

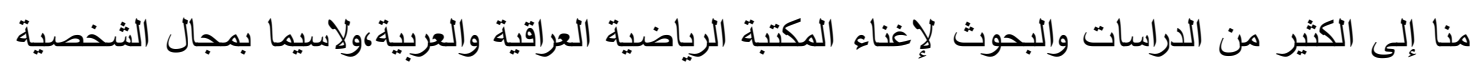

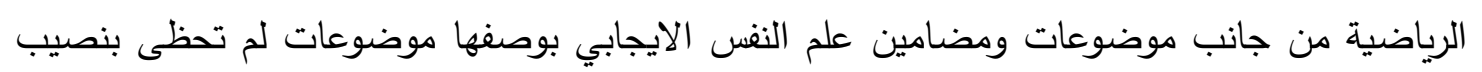
كاف من التحليل،والتقسير،والتعمق المعرفي وتحددت مشكلة البحث في الدراسة الحالية على محاولة الاجابة عن بعض التساؤلات عن ماهي السمات الايجابية في الثخصية المميزة للاعبين في رياضة المعاقين؟وماهي طبيعة التصنيفات الاعاقة في الالعاب الفرقية التي قد تؤثر في فاعلية دور السمات الايجابية سلباً أم ايجاباً ؟ مما ينعكس بدوره على نفسية اللاعبين المعاقين. وأخيراً ولعدم توافر مقياس نوعي خاص لقياس السمات الايجابية للاعبين المعاقين في بعض للألعاب الفرقية ، فقد وجهت الدراسة

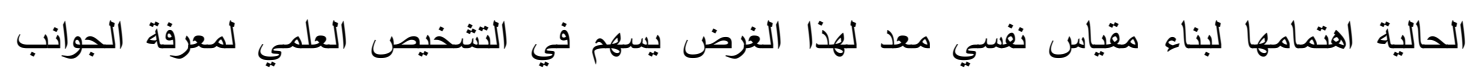
الايجابية للشخصية الرياضية للاعبين المعاقين والعمل على تعزيز وتطوير هذه الجوانب الايجابية.

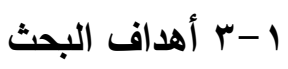

- - بناء مقياس السمات الايجابية في الثخصية للاعبين المعاقين في بعض الألعاب الفرقية بالعراق . - التعرف على درجة السمات الايجابية في الثخصية للاعبين المعاقين في الألعاب الفرقية بالعراق .

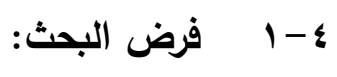

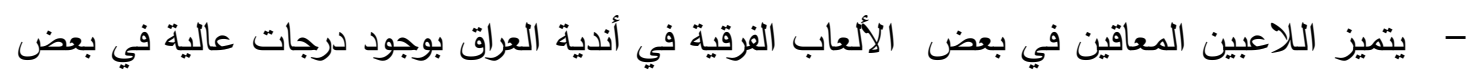
السمات الشخصية الايجابية . الشيرية

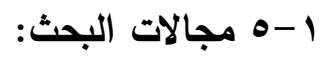

ا ـ المجال البشري:لاعبو أندية المعاقين للألعاب الفرقية( كرة سلة كراسي متحركة،وكرة طائرة جلوس) بالعراق

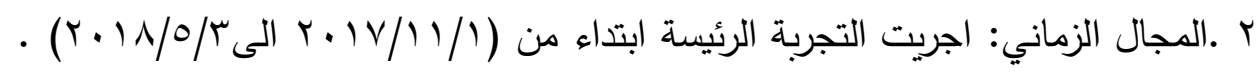

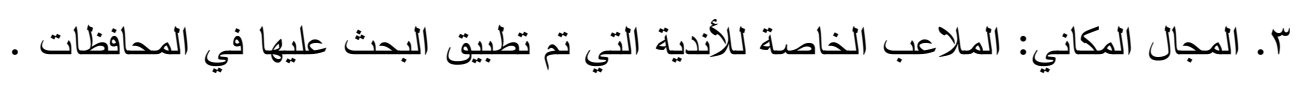
(بغداد ، ونينوى ، والانبار ، وذي قار ، وبابل ، وديالى ، والنجف ، والكوت ، وميسان) في العراق. 1- 1

السمة : انها "الصفة الجسمية أو العقلية أو الانفعالية أو الاجتماعية الفطرية أو المكتسبة التي يتميز بها

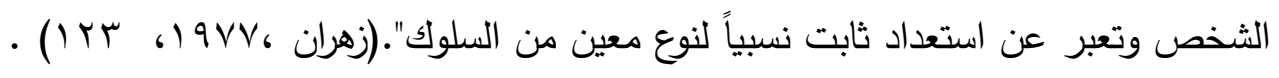

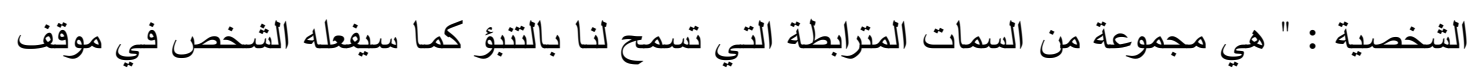

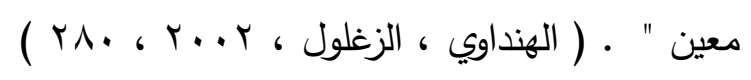

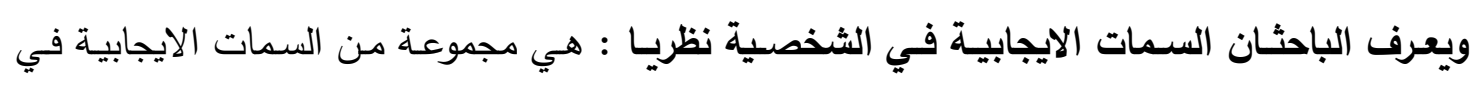
الثخصية التي يتميز بها لاعبي أنديـة المعـاقين للألعاب الفرقيـة ( كرة السلة كراسي متحركة ، و و كرة

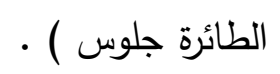

ويعرف الباحثان السمات الايجابية في الثخصية اجرائيا :، الدرجة التي يحصل عليها من افراد عينة

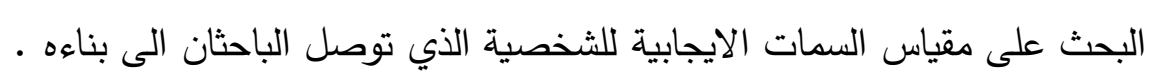




\section{r.1 منهج البحث: استخدم الباحثان المنهج الوصفي بالأسلوب المسحي لملاءمته وطبيعة البحث .}

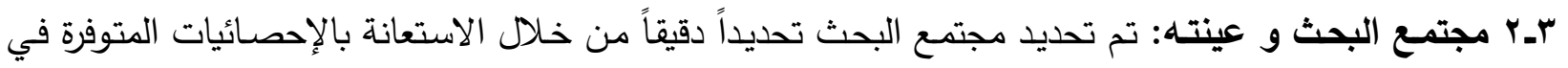
اللجنة البارالمبية في بغداد والجدول (1) يبين ذلك، إذ اشتمل مجتمع البحث على لاعبي اللجان الفرعية للبارالمبية لاتحادي كرة السلة كراسي متحركة و كرة الطائرة جلوس على مستوى العراق ،و البالغ عددهم (19 ())لاعباً ،والذي لئي يمثل نسبة( · ( (\%) من مجتمع البحث ،والذي يمثل عينة البحث الكلية والتي ضمت لاعبي كلاهما وموزعين على حره اللجان الفرعية لكل اتحاد والجدول ( 1 ) يبين اعداد اللاعبين في كلا الاتحادين بالنسبة لكل لجنـة و نسبهم المئويـة.

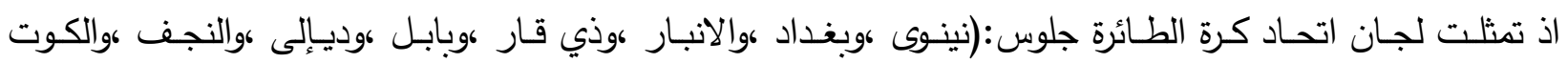

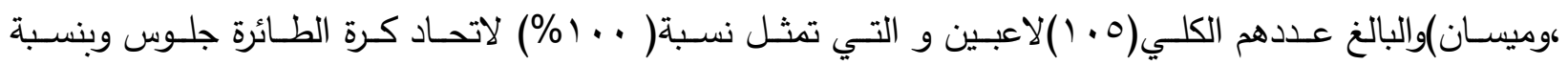

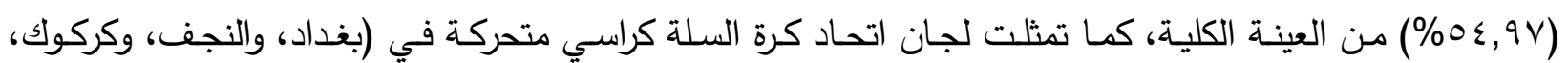

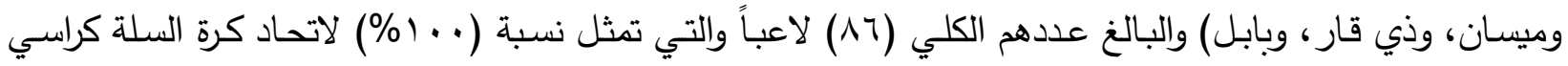

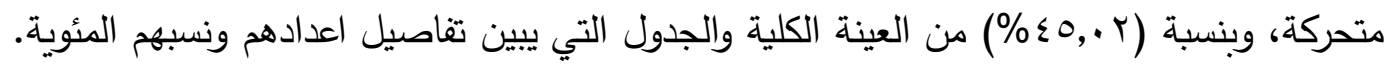

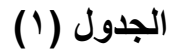

اسم الاتحاد واللجنة واللعبة وأعداد اللاعبين ونسبهم المئوية

\begin{tabular}{|c|c|c|c|c|}
\hline \multicolumn{2}{|c|}{ مجتمع البحث } & \multirow[b]{2}{*}{ اسم اللجنة } & \multirow[b]{2}{*}{ الاتحاد } & \multirow[b]{2}{*}{ ت } \\
\hline النسبة & العدد العد & & & \\
\hline$\% \curlyvee, Y \wedge$ & Ir & لجنة نينوى & \multirow{9}{*}{ اتحاد كرة الطائرة جلوس } & \multirow{9}{*}{1} \\
\hline$\% 1 \cdot, \leqslant V$ & $r \cdot$ & لجنة بغداد & & \\
\hline$\% \curlyvee, \curlyvee \wedge$ & Ir & لجنة الانبار & & \\
\hline$\% \otimes, Y r$ & 1. & لجنة ذي قار & & \\
\hline$\% \%^{0, Y T}$ & 1. & لجنة بابل & & \\
\hline$\% 0, Y^{\top}$ & 1. & لجنة ديالى & & \\
\hline$\% 0, Y r$ & 1. & لجنة النجف & & \\
\hline$\% \otimes, Y r$ & 1. & لجنة الكوت & & \\
\hline$\% \bullet, Y r$ & 1. & لجنة ميسان & & \\
\hline$\% \circ\{, 9 V$ & 1.0 & \multicolumn{3}{|c|}{ الدجموع } \\
\hline$\% \backslash 1,01$ & Yr & لجنة بغداد & \multirow{6}{*}{ اتحاد كرة السلة كراسي } & \multirow{6}{*}{.$r$} \\
\hline$\% \vee, \wedge \diamond$ & 10 & لجنة النجف & & \\
\hline$\% \leqslant, 1 \wedge$ & $\wedge$ & لجنة كركوك & & \\
\hline$\% \curlyvee, \wedge$. & 14 & لجنة ميسان & & \\
\hline$\% \vee, \wedge \bullet$ & 10 & لجنة ذي قار & & \\
\hline$\% \curlyvee, \wedge$ & 14 & لجنة بابل & & \\
\hline$\% \leqslant 0, \cdot r$ & 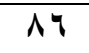 & & المجموع & \\
\hline
\end{tabular}

إذ يتكون المجتمع من لاعبي بعض الألعاب الرياضية الفرقية والمتمثلة بفعاليتي كرة الطائرة جلوس وكرة السلة

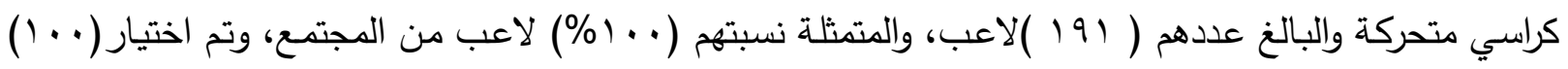

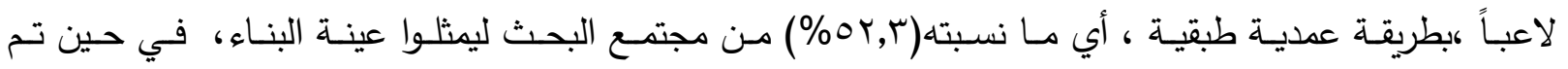
اختيار (آ7) لاعباً ،من مجتمع البحث أي ما نسبته (9, (1\%\%) من مجتمع البحث ليمثلوا عينة التطبيق ، تم اختيار

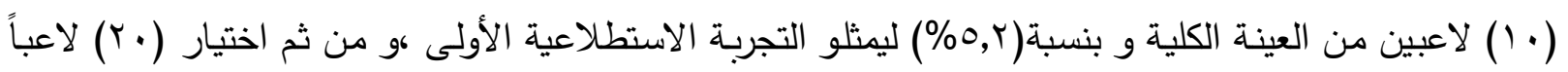
من العينة الكلية و بنسبة (ع, • (\%) ليمثلو التجربة الاستطلاعية الثانية والتي تمثل الثبات. 


\section{الجدول(r)}

يبين تفاصيل عينة البحث

\begin{tabular}{|c|c|c|c|c|}
\hline النسبة المئوية & عدد اللاعبين & هدفها & 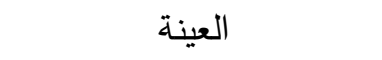 & $ت$ \\
\hline$\% 0, r$ & 1. & التحقق من التعليمات & الاستطلاعية الأولى والثانية & 1 \\
\hline$\%) \cdot,\{$ & r. & التبــــــــــات & 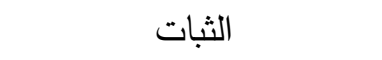 & r \\
\hline$\% \circ r, r$ & $1 \ldots$ & التحليل الإحصائي للمقاييس & صد الصدق البناء ( التمييز ) & $\varepsilon$ \\
\hline$\%$ \% , 9 & 71 & ايجاد الفروق بين التصنيفات & التطبيق & 7 \\
\hline$\% 1 \ldots$ & 191 & & 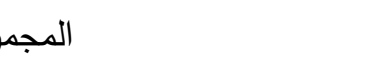 & \\
\hline
\end{tabular}

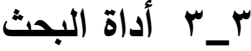

تم اعتماد الدقياس كأداة للبحث من أجل الوصول إلى السمات الايجابية للثخصية للاعبين

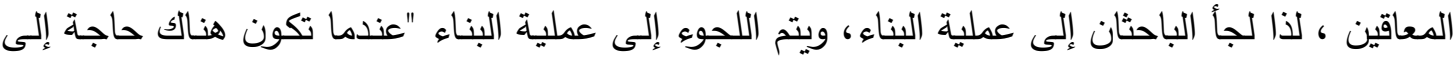
تطوير وسائل القياس المتاحة ،والعمل على ابتكار وسائل وادوات جديدة للاستفادة منها في البيئة المحلية

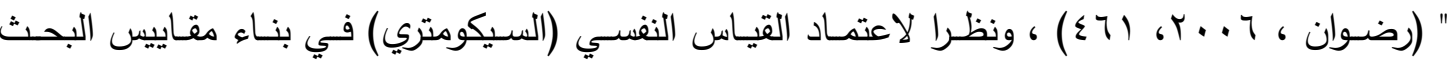

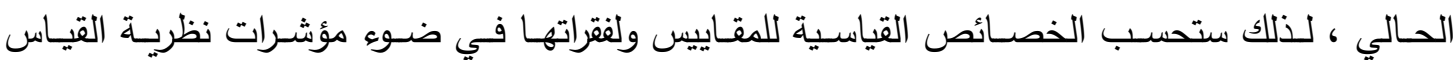
الكلاسيكية ،ووفقا لأسلوب التقرير الذاتي .

\section{r_r_r} من أجل تحديد السمات الايجابية للشخصية للمقياس المزمع بناءه ، قام الباحثان بالاطلاع

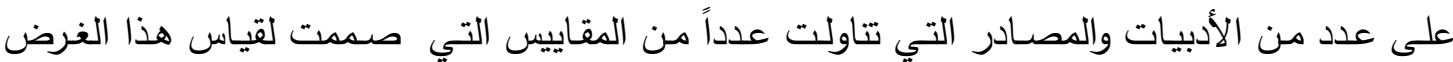

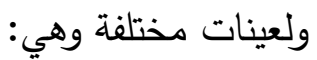
- الدراسـات النظريـة التي تناولتها مصـادر علم النفس الايجابي ،وعلم النفس الثخصية ،وعلم النفس

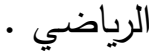
-الدراسات السابقة التي تتاولت السمات الايجابية للثخصية منفردة كل دراسة بسمة واحدة او اكثر.

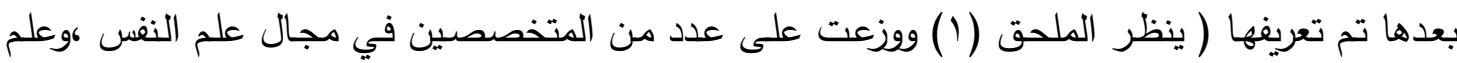

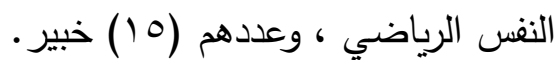

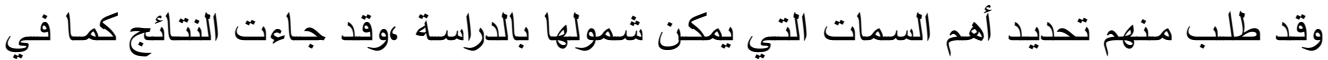

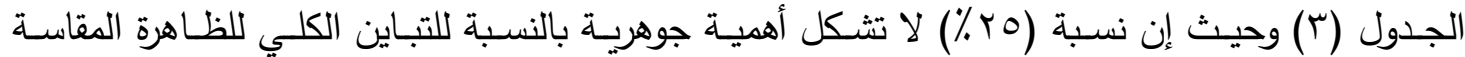

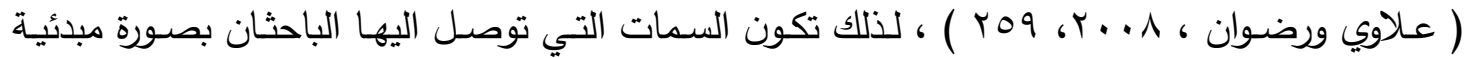

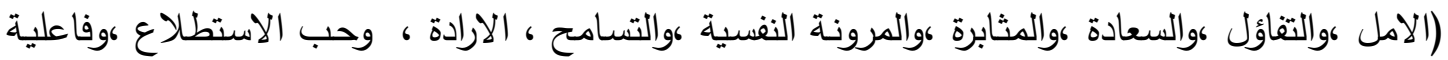

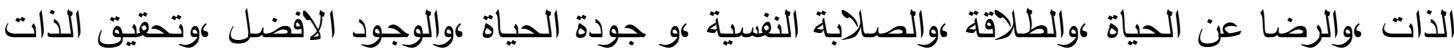




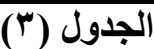

يبين التكرارات السمات الايجابية للشخصية التي يمكن شمولها بالدراسة

\begin{tabular}{|c|c|c|c|}
\hline النسبة المئوية & المو افقون & السمات & ت \\
\hline$\%$ & $1 \%$ & الأمل & 1 \\
\hline$\%$ & 10 & التفاوئ & $r$ \\
\hline \% \%r. & $r$ & السعادة & $\bar{\mu}$ \\
\hline$\%$ & 10 & المثابرة & $\varepsilon$ \\
\hline$\% \vee V r$ & 11 & المرونة النفسية & 0 \\
\hline$\%$ \%. & $r$ & التسامح & 7 \\
\hline$\% 94$ & $1 \varepsilon$ & الارادة & $\mathrm{V}$ \\
\hline$\%$ & 1 & حب الاستطلاع & 1 \\
\hline$\% \vee r$ & 11 & فاعلية الذات & 9 \\
\hline \%/1 & $r$ & الرضا عن الحياة & 1. \\
\hline$\%$ \%. & $r$ & جودة الحياة & 11 \\
\hline$\%$ & 9 & الصلابة النفسية & $1 \%$ \\
\hline$\%$ \%. & IY & الطلاقة & 11 \\
\hline$\%$ & . & الوجود الافضل & $1 \varepsilon$ \\
\hline$\%$ \%1r & $r$ & تحقيق الذات & 10 \\
\hline$\% \% 77$ & 1. & تقدير الذات & 17 \\
\hline
\end{tabular}

بـr_r_r تحديد فقرات السمات الايجابية للشخصية : تم تحديد فقرات مقياس السمات الايجابية بالاعتماد على الادبيات الخاصة بالسمات ،وكذلك بالاعتماد على المقاييس السابقة لكل ، سمة من

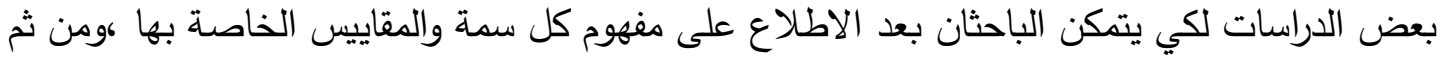

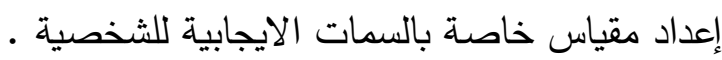
r_r_r_r إعداد الصيغة الأولية للمقياس:يتمثل ذلك في عملية إعداد الفقرات وبدائل الإجابة وإعداد تعليمات الإجابة عن المقاييس ،والصدق المنطقي،ثم التحقق من وضوح التعليمات وفهم اللاعبين للعبارات.  الباحـث أن يكـون علـى وعـي تـام بشـروط إعـداد الفقـرات ومواصــفاتها، إذ إن الخصــائص القياسـية (السيكومترية) للمقياس تعتمد إلى حد كبير على الخصائص القياسية (السيكومترية) لفقراته (عبد الرحمن،

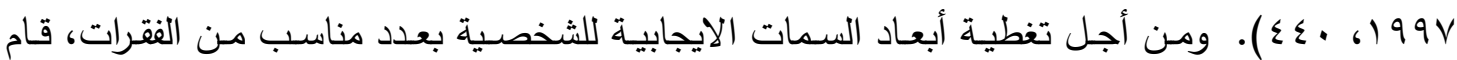
الباحثان بـالاطلاع على الأدبيات ،والمقاييس السـابقة ،فضـلاً عن الخبرة الشخصـية بإعداد عدد مـن الفقرات لكل بعد من الابعاد المشمولة بالدراسة بصيغتها الأولية وكما يأتي:

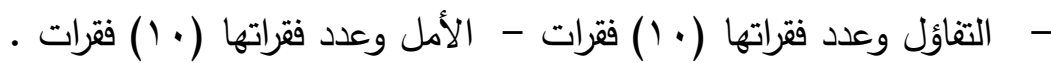
- - الصلابة وعدد فقراتها (• (1) فقرات- المرونة وعدد فقراتها (• (1) فقرات. - تقدير الذات وعدد فقراتها (• (1) فقرات - الطلاقة وعدد فقراتها (• (1) فقرات. - فاعلية الذات وعدد فقراتها (• (1) فقرات - الارادة وعدد فقراتها (• ( ) فقرات. - المثابرة وعدد فقراتها ( • (1) فقرات .

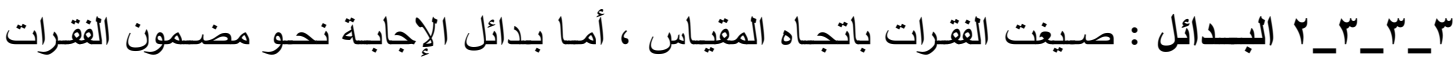
وأعطيت (0) درجات إلى الاجابة ( تتطبق عليّ تماماً ) والدرجة (ع) إلى الاجابة ( تتطبق عليّ كثيراً ) 


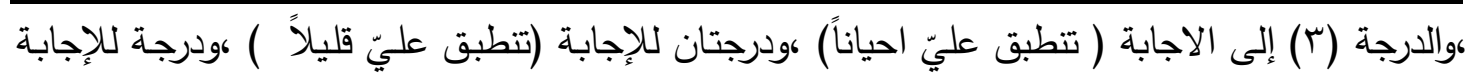

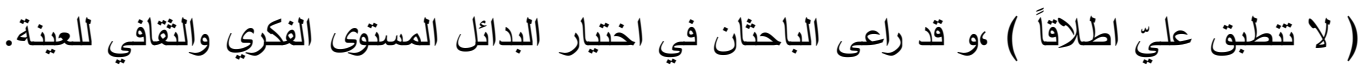

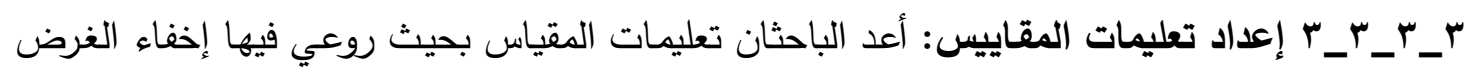

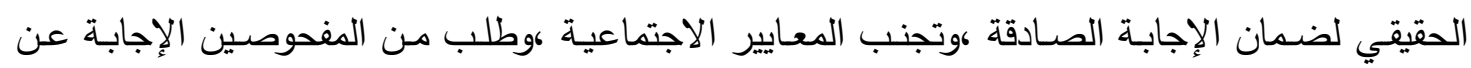

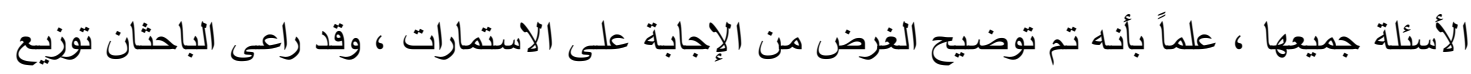

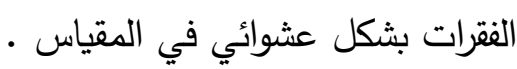

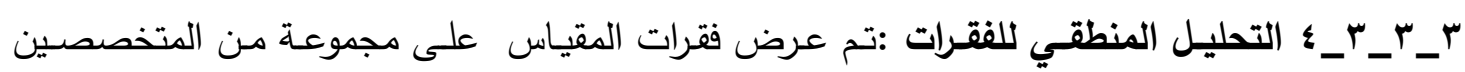

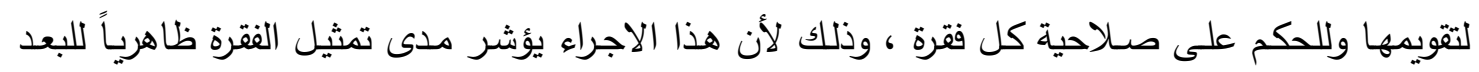

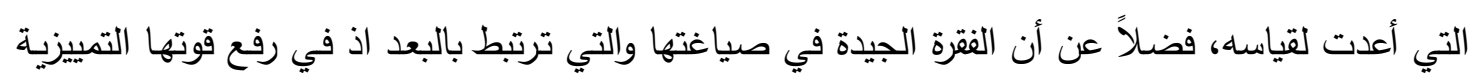

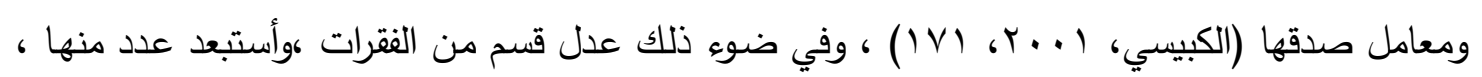

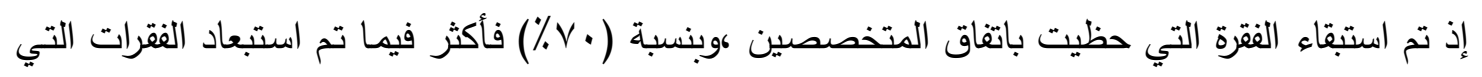

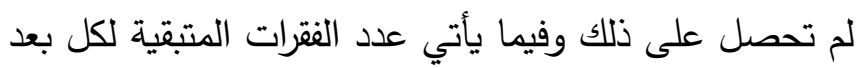

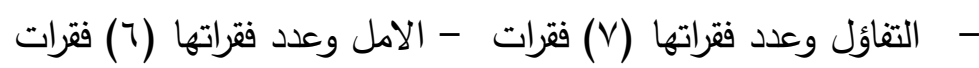

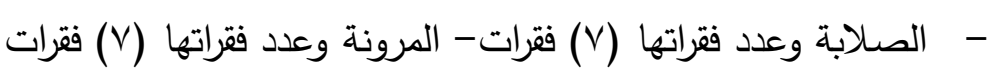

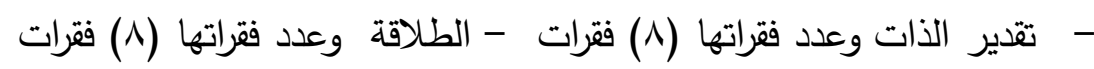

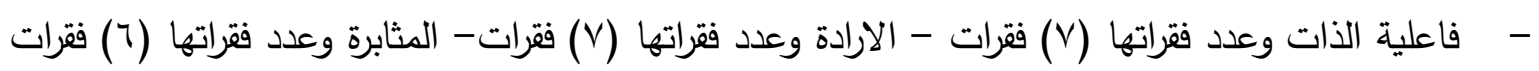

\begin{tabular}{|c|c|c|c|}
\hline عدد الفقرات & الفقرّات المستبعدة & المفياس & $ت$ \\
\hline$r$ & 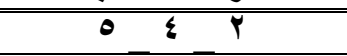 & التنفاؤل & 1 \\
\hline$\xi$ & $1911 \quad 19 \quad 11$ & الامل & T \\
\hline $\bar{\Gamma}$ & $r \cdot r \wedge r 4$ & الصلابة & $\bar{T}$ \\
\hline$r$ & $\varepsilon \varepsilon_{0} \quad r \Lambda \quad r \varepsilon$ & المرونة & $\xi$ \\
\hline T & $0 . \quad \leq 9$ & تقلفير الذات & 0 \\
\hline $\bar{T}$ & 0904 & الطلافة & 7 \\
\hline $\bar{r}$ & $\begin{array}{lll}79 & 70 \quad 71\end{array}$ & فاعلية الذات & $\bar{v}$ \\
\hline $\bar{r}$ & $\begin{array}{llll}\Lambda . & V \wedge & V 4\end{array}$ & الاررادة & $\bar{\Lambda}$ \\
\hline$\xi$ & $\begin{array}{llll}9 . & \wedge \Lambda & \wedge \theta & \Lambda \varepsilon\end{array}$ & المثّابرة & 9 \\
\hline
\end{tabular}

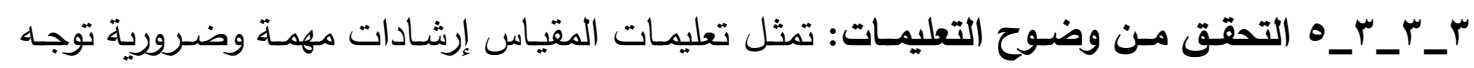

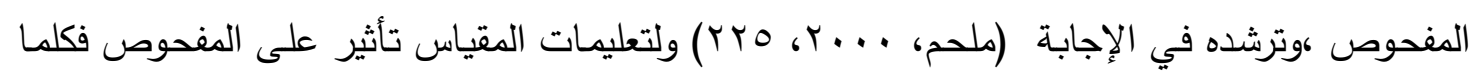

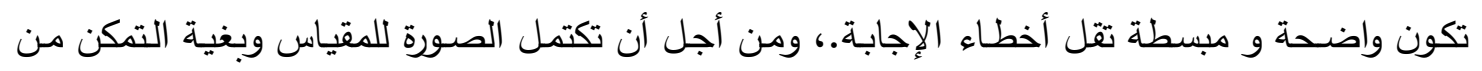

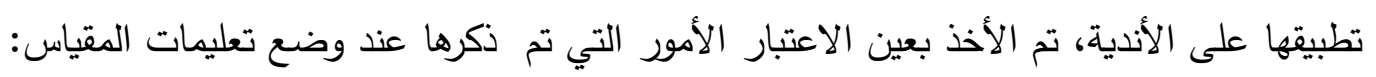

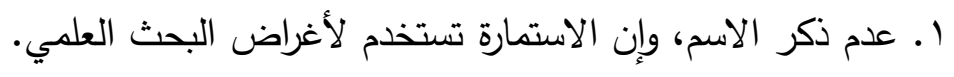

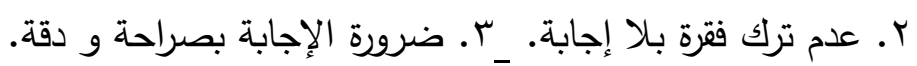

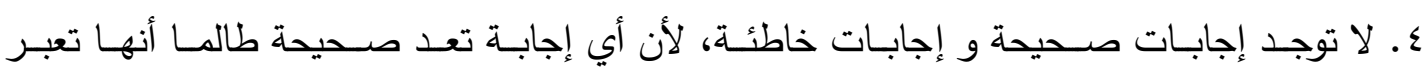
عن رأيك في نفسك بصدق. 0. 


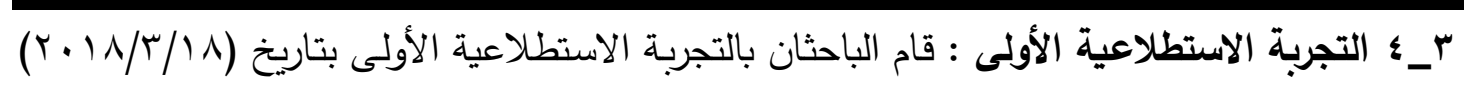
لغرض التعرف على مدى وضسوح تعليمات مقياس السمات الايجابية في الثخصية بصورتها الأولية

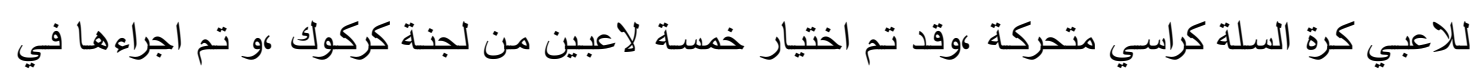
مركز تأهيل المعاقين بكركوك ، وقام الباحثان باختيار لاعبين لكي يتم التأكد من وضوح التعليمات لهم

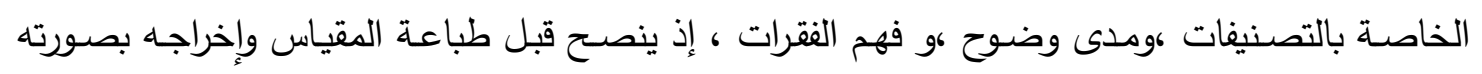
النهائية بتطبيق فقراته على عينة صغيرة(النبهان، ع . . Y، 0 1 ( )وكانت طريقة الإجابة واضحة ومفهومة. r_o_ التحليل الإحصائي للفقرات: كان لابد من إجراء التحليل الإحصائي للفقرات ،إذ إن التحليل المنطقي للفقرات قد لا يكثف أحياناً عن صلاحيتها أو صدقها بشكل دقيق ، في حين أنَّ التحليل Ebel, ) الإحصائي للدرجات التجريبية يكثف عن دقة الفقرات في قياس ما وضعت من اجل قياسه 406 , 1972 ) تم تطبيق المقياس على عينة تبلغ ( · () لاعب،ويبين الجدول ( 0 ) مواصفات هذه

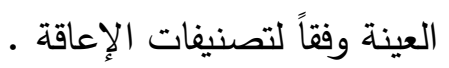

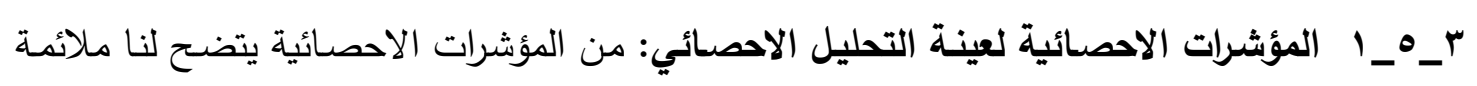
درجات افراد العينة للتحليل الاحصائي والمبينة في الجدول الأتي:

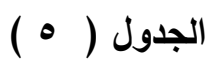

\begin{tabular}{|c|c|}
\hline الارجة & المؤشر ات الاحصائية \\
\hline YqV,Aq & المتوسط \\
\hline $1 V, 0 \leq$ & الاتحراف المعياري \\
\hline $1, \vee 0 \leq$ & الخطأ المعياري \\
\hline . & التفرطح \\
\hline$\cdot, V_{1}$ & الالتواء \\
\hline ror & المدى/ المعدل \\
\hline Mlo & أعلى درجة \\
\hline 74 & أقل درجة \\
\hline
\end{tabular}

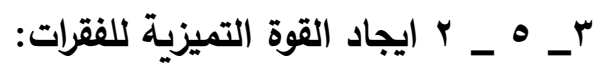

تتضمن الخصـائص السـايكومترية، حساب القوة التمييزيـة للفقرات، إذ تشير القوة التمييزيـة إلى القدرة على التفريق ،أو التمييز بين الأفراد الذين يحصلون على درجات عالية ،والأفراد الذين يحصلون

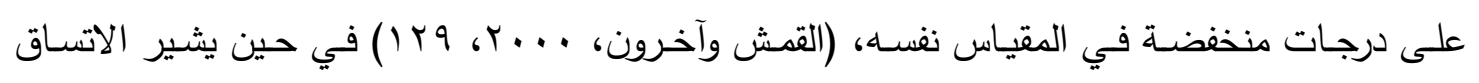
الداخلي إلى مدى تجـانس الفقرات في قياسها للصفة ،ويتم ذلك باستخدام معامل الارتباط بين الفقرة

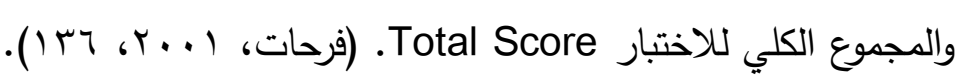

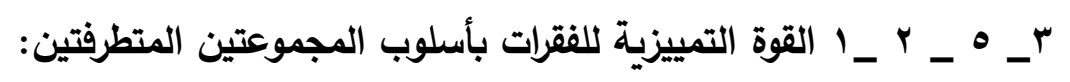
بعد تصحيح استمارات الإجابة ، رتبت درجات أفراد العينة تنازلياً بغية احتساب القوة التمييزية لفقرات المقياس وفقاً للدرجة الكلية ،وحددت المجموعتان الطرفيتان وبنسبة (•r\%) ليبلغ عدد المجموعة الواحدة (• r) لاعباً ،فيما تم استبعاد أفراد النسبة الوسطية المتبقية، واستخدم الاختبار التائي (t-Test) 
لعينتين مستقلتين في حساب الفرق بين المجموعتين في درجات كل فقرة من فقرات المقياس، على أساس أن القيمة التائية المحسوبة تمثل القوة التمييزية للفترة.

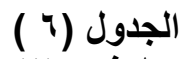

القوة التمييزية بأسلوب المجموعتين المتطرفتين لفقرات مقياس السمات الايجابية للشخصية

\begin{tabular}{|c|c|c|c|c|c|c|c|}
\hline \multirow{2}{*}{ المستبار ات ات المدة } & \multirow{2}{*}{ الاحتمـال } & \multirow{2}{*}{ المحسمة تبة } & \multicolumn{2}{|c|}{ المجموعة الدنيا } & \multicolumn{2}{|c|}{ المجموعة العليا } & \multirow{2}{*}{ رقفم } \\
\hline & & & $\varepsilon \pm$ & س' & $\varepsilon \pm$ & س' & \\
\hline تم استبعادها & $1, \geq 9$ & $1, \leq 9$ & $\cdot, \varepsilon \wedge$ & $\varepsilon, 7 V$ & $\cdot, \mu \wedge$ & $\varepsilon, \wedge \mu$ & 1 \\
\hline تم استبعادها & $\cdot, \wedge 0$ & $\cdot, \wedge 0$ &., $7 r$ & $\varepsilon, 7$ & $\cdot, 0 \wedge$ & $\varepsilon, v r$ & r \\
\hline تم استبعادها & $\cdot, \leqslant 0$ & $\cdot, \leqslant 0$ & $\cdot, 0 V$ & $\varepsilon, \otimes r$ &., 07 & $\varepsilon, 7$ & $r$ \\
\hline تم استبعادها & $1, \cdot r$ & $1, \cdot r$ & $\cdot, v r$ & $\varepsilon, \leqslant V$ & $\cdot, \leqslant 9$ & $\varepsilon, 7 r$ & $\varepsilon$ \\
\hline تم استبعادها & $1, \cdot \varepsilon$ & $1, \cdot \varepsilon$ & $\cdot, \wedge ।$ & $r, \Lambda$ & $1,1 \varepsilon$ & $\varepsilon, \cdot v$ & 0 \\
\hline \multirow[t]{2}{*}{ تم استبعادها } & $1, \wedge 1$ & $1, \wedge 1$ &., $7 r$ & $\varepsilon, 0$ & $\cdot, 0$ & $\varepsilon, v \vee$ & 7 \\
\hline & $\varepsilon, r q$ & $\varepsilon, r q$ & $1, r r$ & $r, v$ & $\cdot, \varepsilon \wedge$ & $\varepsilon, \Lambda$ & v \\
\hline \multirow[t]{12}{*}{ تم استبعادها } & $1, \cdot v$ & $1, \cdot v$ & $\cdot, \leqslant \wedge$ & $\varepsilon, 7 V$ & $\cdot, \leqslant \Lambda$ & $\varepsilon, \Lambda$ & $\wedge$ \\
\hline & $r, \varepsilon r$ & $r, \varepsilon r$ & $\cdot, \vee \wedge$ & $r, v r$ & $\cdot, V r$ & $\varepsilon, \varepsilon$ & 9 \\
\hline & $r, 10$ & $r, 10$ & $1, r$ & $r, v V$ &., $7 r$ & $\varepsilon, 7$ & 1. \\
\hline & $r, Y \leq$ & $r, r \leq$ & $1, .9$ & $r, \wedge r$ & $\cdot, \nabla r$ & $\varepsilon, \mu v$ & 11 \\
\hline & $r, 7$. & $r, 7$. & $\cdot, v r$ & $\varepsilon, \diamond V$ & $\cdot$, ro & $\varepsilon, q \mu$ & Ir \\
\hline & $0, r q$ & $0, r q$ & $1, \cdot v$ & $r, q V$ & $\cdot, \wedge \wedge$ & $\varepsilon, r$ & ir \\
\hline & $\varepsilon, \varepsilon \mu$ & $\varepsilon, \varepsilon r$ & 1,10 & $r, \wedge r$ & $\cdot, \leqslant 7$ & $\varepsilon, \wedge r$ & $1 \varepsilon$ \\
\hline & $v, 1 \mathrm{r}$ & $v, 1 \mathrm{r}$ & $\cdot, \wedge 9$ & r, & $\cdot, \nabla r$ & $\varepsilon, 1 r$ & 10 \\
\hline & $r, \leqslant \wedge$ & $r, \varepsilon \Lambda$ & $\cdot, \wedge 1$ & $\varepsilon,+r$ &., 01 & $\varepsilon, \varepsilon V$ & 17 \\
\hline & $v, 0$. & $v, 0$. & $\cdot, \vee \vee q$ & $r, r$ & $\cdot, \nabla r$ & $\varepsilon, 7 \mu$ & IV \\
\hline & $r, \varepsilon q$ & $r,\{q$ &., 79 & $\varepsilon, Y V$ &., 70 & $\varepsilon, V$ & 11 \\
\hline & $r, 10$ & $r, 10$ & $\cdot, 71$ & $\varepsilon, \diamond V$ & . , ro & $\varepsilon, \wedge \vee$ & 19 \\
\hline \multirow[t]{3}{*}{ تم استبعادها } & 1,09 & 1,09 & $\cdot, 7 \leq$ & $\varepsilon, V \mu$ & $\cdot, r o$ & $\varepsilon, q r$ & $r$. \\
\hline & $7,0 r$ & $7, O r$ & $\cdot, 9 V$ & $r, \otimes r$ & $\cdot, \wedge 0$ & $\varepsilon, \cdot r$ & YI \\
\hline & $r, \varepsilon$. & $Y, \varepsilon$. & $1, Y r$ & $\varepsilon, r r$ & $\cdot, \leqslant 1$ & $\varepsilon, \Lambda$ & Yr \\
\hline تم استبعادها & $\cdot, \leqslant \leqslant$ & $\cdot, \leq \varepsilon$ & . & $\varepsilon, V V$ & $\cdot, 0 r$ & $\varepsilon, \wedge r$ & $r r$ \\
\hline \multirow[t]{3}{*}{ تم استبعادها } & $1, \vee 9$ & $1, \vee 9$ & $\cdot, 71$ & $\varepsilon, \Lambda$ & $\cdot, O r$ & 0 & $r \varepsilon$ \\
\hline & $Y, \diamond \wedge$ & $r, \diamond \wedge$ & $\cdot, 0 r$ & $\varepsilon, V$ & $\cdot, 1 \wedge$ & $\varepsilon, 9 \vee$ & ro \\
\hline & $r, 0 \varepsilon$ & $r, 0 \varepsilon$ &., 99 & $r, q V$ & $\cdot, 7$ & $\varepsilon, V$ & Yq \\
\hline \multirow[t]{3}{*}{ تم استبعادها } & $\cdot, r \wedge$ & $\cdot, \mu \wedge$ & $\cdot, \varepsilon$ & $\varepsilon, 9$ &.,$r_{0}$ & $\varepsilon, 9 r$ & YV \\
\hline & $r, 19$ & $r, 17$ & $1, r$ & $\varepsilon, Y V$ &., 71 & $\varepsilon, \Lambda$ & $r \wedge$ \\
\hline & $\varepsilon, \cdot V$ & $\varepsilon, \cdot V$ & $\cdot, \vee \vee q$ & $r, \wedge r$ &., 01 & $\varepsilon, O r$ & rq \\
\hline
\end{tabular}




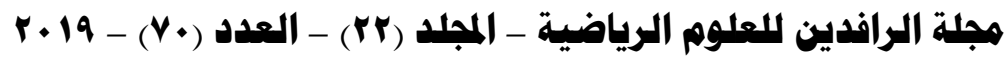

السمات الايجابية للشخصية للاعبين المعاقين في بعض الالعاب الفرقية بالعراق

\begin{tabular}{|c|c|c|c|c|c|c|c|}
\hline & $r, \wedge I$ & $Y, \wedge 1$ & $1, M_{1}$ & $\varepsilon, 1 \%$ &.,$V_{0}$ & $\varepsilon, \wedge V$ & r. \\
\hline تم استبعادها & $1,0 \leq$ & $1,0 \leq$ & $1,+r$ & $\varepsilon, 7 \mu$ & $\bullet, Y 0$ & $\varepsilon, q 4$ & ו \\
\hline \multirow[t]{6}{*}{ تم استبعادها } & $1, \leqslant \Lambda$ & $1, \leqslant \Lambda$ & 1,1 & $r, v V$ & $1, \cdot \varepsilon$ & $\varepsilon, Y r$ & rr \\
\hline & $Y, V \varepsilon$ & $r, V \varepsilon$ & $1,1 \leq$ & $\varepsilon, \cdot v$ & $\bullet, \Delta \mu$ & $\varepsilon, V$ & بr \\
\hline & $r, 0$ & $r, 0$ &., 07 & $\varepsilon, 7 \mu$ & $\bullet$ & $\varepsilon, \wedge V$ & ع \\
\hline & $r, 7 r$ & Y &., $7 V$ & $r, \mu v$ & $\cdot, \wedge \wedge$ & r,q & po \\
\hline & $r, 19$ & $r, 19$ & $\cdot, 9 r$ & $\varepsilon, \mu$ & $\bullet, \circ \mathrm{V}$ & $\varepsilon, V V$ & צ \\
\hline & 0,94 & 0,94 & $\cdot, \vee v 0$ & $r, V$ & $1, \cdot 1$ & $\varepsilon, \cdot V$ & rv \\
\hline \multirow[t]{2}{*}{ تم استبعادها } & $\cdot, \leqslant 9$ & 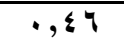 & $\cdot, \Psi_{1}$ & $\varepsilon, 9$ & $\bullet, Y 0$ & $\varepsilon, 94$ & H人 \\
\hline & $1,9 \leq$ & $1,9 \leq$ & $\cdot, 9 V$ & $\varepsilon, 0$ & $\bullet$ & $\varepsilon, \wedge V$ & pq \\
\hline \multirow[t]{8}{*}{ تم استبعادها } & 1,09 & 1,09 & $\cdot, \vee r$ & $\varepsilon, \otimes r$ & $\bullet, \infty \bullet$ & $\varepsilon, \Lambda$ & $\varepsilon$. \\
\hline & $\varepsilon, \wedge \bullet$ & $\varepsilon, \wedge \bullet$ &., 79 & $\varepsilon$ & $\bullet, \leqslant 0$ & $\varepsilon, V \Psi$ & \&1 \\
\hline & $7, r$ & $7, \Psi$. & $\cdot, \vee \wedge$ & $r, 0$ & $\cdot, 0$ & $\varepsilon, \diamond V$ & $\varepsilon r$ \\
\hline & $1 \varepsilon, 7 V$ & $1 \varepsilon, 7 V$ & $\cdot, 0$ & $1, v V$ & $\cdot, \wedge 7$ & $\varepsilon, \varepsilon \Psi$ & $\varepsilon r$ \\
\hline & $\varepsilon, q \mu$ & $\varepsilon, q \mu$ &., 71 & $r, r$ & $1, r q$ & $r, \mu$ & $\varepsilon \varepsilon$ \\
\hline & $r, r V$ & $r, r V$ & $\cdot, \wedge 7$ & $\varepsilon, \varepsilon$ & $\bullet, Y 0$ & $\varepsilon, q 4$ & $\leqslant 0$ \\
\hline & 9,1 . & 9,1 . & Tr & $1, \wedge V$ & $\cdot, \wedge r$ & $\varepsilon, \varepsilon V$ & $\leqslant 7$ \\
\hline & $Y, V Y$ & $Y, V Y$ & $\cdot, v$ & $\varepsilon, I V$ & $\cdot, 0$ & $\varepsilon, 7$ & $\varepsilon V$ \\
\hline \multirow[t]{4}{*}{ تم استبعادها } & $1,1 \leq$ & $1,1 \leq$ & 1,0 & $r, \otimes r$ & $1, \varepsilon$ & $r, 9 V$ & $\varepsilon \wedge$ \\
\hline & $r, \varepsilon$ & $r, \varepsilon$ & $\cdot, \vee 7$ & r & $\bullet, \wedge 0$ & $r, q V$ & $\leqslant 9$ \\
\hline & $r, \Lambda$ & $r, \Lambda$ & $\cdot, 97$ & $\varepsilon, \mu$ & $\cdot, M_{1}$ & $\varepsilon, q$ & 0 . \\
\hline & $\varepsilon, V$. & $\varepsilon, V$. &., $7 V$ & $r, \mu v$ &., 70 & $\varepsilon, 1 v$ & 01 \\
\hline \multirow[t]{3}{*}{ تم استبعادها } & $1,0 \mathrm{~V}$ & $1,0 V$ &., 00 & $\varepsilon, \Lambda$ &., 11 & $\varepsilon, 9 v$ & Or \\
\hline & $\varepsilon, \varepsilon \Psi$ & $\varepsilon, \varepsilon r$ & $\cdot, 09$ & $r, \wedge r$ & $\cdot, \circ V$ & $\varepsilon, 0$ & H \\
\hline & $r, q 0$ & r,qo & $1, \cdot v$ & $r, \varepsilon r$ & $\cdot, \wedge r$ & $\varepsilon, 1 v$ & $0\}$ \\
\hline \multirow[t]{2}{*}{ تم استبعادها } & $1, \cdot \varepsilon$ & $1, \cdot \varepsilon$ & 0,197 & $\varepsilon, \wedge r$ &.,$Y O$ & $\varepsilon, q 4$ & 00 \\
\hline & $9, \leqslant 1$ & $9, \leqslant 1$ & $\cdot, \leqslant 1$ & $\varepsilon, Y$ & $\cdot, 11$ & $\varepsilon, 9 V$ & 07 \\
\hline \multirow[t]{7}{*}{ تم استبعادها } & $1, \cdot \varepsilon$ & $1, \cdot \varepsilon$ & $0, \leqslant 7$ & $\varepsilon, \wedge r$ & $\bullet, Y 0$ & $\varepsilon, 9$ & OV \\
\hline & $Y, V Y$ & $Y, \vee Y$ &., 77 & $\varepsilon, 7 V$ & $\cdot, \mu r$ & 0 & $0 \wedge$ \\
\hline & $q,+9$ & $9,+9$ & $\cdot, \varepsilon$ & 1,9 & $1, \cdot v$ & $\bar{r}, \wedge v$ & 09 \\
\hline & $V, 9 \leq$ & $V, q \varepsilon$ & $\cdot, \vee \vee q$ & $r, I V$ & $\cdot, \wedge \mu$ & $r, \wedge \mu$ & 7. \\
\hline & $r, I V$ & $Y, I V$ & $1, \cdot v$ & $\varepsilon, \nabla r$ &., 11 & $\varepsilon, 9 V$ & 71 \\
\hline & 1,91 & 1,91 &., $7 \mathrm{~V}$ & $\varepsilon, 7 r$ & $\cdot, \mu_{1}$ & $\varepsilon, 9$ & $9 r$ \\
\hline & $7, \wedge 9$ & $7, \wedge 9$ & $\cdot, 9$ & $r, \& V$ & $\cdot, \leqslant 0$ & $\varepsilon, V \Psi$ & עד \\
\hline
\end{tabular}

الفقرة المقبولة ، هي الفقرة التي تحقق قيمة احتمال (0.05) 


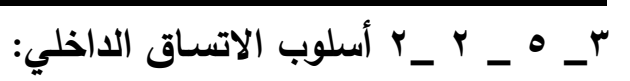

ويتم احتسـابه مـن خـلال ايجـاد العلاقـة الارتباطية لدرجـة الفقرة بالدرجـة الكلية للمقيـاس، الذي

يحدد مسار الفقرة كونها باتجاه المقياس أم لا وقد تم إيجاد ذلك ،وكما في الجدول(V)إذ يتضح الإتباط المعنوي بين جميع الفقرات والدرجة الكلية للمقياس مما يحتم بقاءها.

(v) (الجدول

معاملات الارتباط بين درجات فقرات المقياس ودرجته الكلية

\begin{tabular}{|c|c|c|c|c|c|}
\hline مستوى الدلالة & معامل الارتباط & رقم الفقرة & مستوى الدلالة & معامل الارتباط & رقم الفقرة \\
\hline$\cdot, \cdot 1$ & $\cdot, Y_{0}$ & rq & $\cdot, \ldots$ & $\cdot, \leqslant \leqslant$ & v \\
\hline$\cdot, \cdots$ & $\cdot, 0 r$ & $r v$ & $\cdot, \cdots$ & $\cdot, r V$ & 9 \\
\hline$\cdot, \cdot r$ & • & $r q$ & $\cdot, \cdot 1$ & • & 1. \\
\hline., 01 & $\cdot, \cdot V$ & $\leqslant 1$ & $\cdot, \cdot r$ & $\cdot, Y Y$ & 11 \\
\hline$\cdot, \ldots$ & $\cdot, \leqslant \wedge$ & $\varepsilon r$ & $\cdot, \cdot 1$ & $\cdot, Y^{4}$ & Ir \\
\hline • & $\cdot, \theta_{-}$ & $\varepsilon r$ & $\cdot, \cdots$ & $\cdot, \leqslant \wedge$ & $1 r$ \\
\hline$\cdot, \cdots$ & $\cdot, 0$ & $\leqslant \varepsilon$ & $\cdot, \cdots$ & ع & $1 \leq$ \\
\hline$\cdot, \cdots$ & $\cdot, r q$ & $\leqslant 0$ & $\cdot, \cdots$ & r & 10 \\
\hline$\cdot, \cdots$ & $\cdot, \pi r$ & $\varepsilon q$ & $\cdot, \cdot \varepsilon$ & $\cdot, r_{1}$ & 17 \\
\hline$\cdot, \cdots$ & $\cdot r$ & $\varepsilon V$ & $\cdot, \ldots$ & $\cdot, 00$ & iv \\
\hline$\cdot, \cdot \varepsilon$ & $\cdot, r \leqslant$ & $\varepsilon 9$ & $\cdot, \cdot 1$ & $\cdot, Y^{4}$ & 11 \\
\hline$\cdot, \cdot 1$ & - Y Y & 0. & $\cdot, \cdot \varepsilon$ & $\cdot, r_{1}$ & 19 \\
\hline$\cdot, \cdots$ & $\cdot \leq V_{.-}$ & 01 & $\cdot, \cdot r$ & $\cdot, Y_{Y}$ & YI \\
\hline$\cdot, \cdots$ & $\cdot, \mu r$ & or & $\cdot, \cdot \varepsilon$ & $\cdot, M_{1}$ & $r r$ \\
\hline$\cdot, \cdots$ & $\cdot, 4$ & $0 \leq$ & $\cdot, \cdot r$ & . , $1 \leq$ & ro \\
\hline$\cdot, \cdots$ & $\cdot, 00$ & 07 & $\cdot, \cdots$ & - I, & Yq \\
\hline$\cdot, \cdots$ & $\cdot, r$ & $0 \wedge$ & $\cdot, \cdot 1$ & $\cdot, r V$ & $r \wedge$ \\
\hline$\cdot, \cdot r$ & $\cdot, r \leq$ & 09 & $\cdots$ & $\cdot, \mu_{0}$ & rq \\
\hline$\cdot, \cdots$ & r & 7. & $\cdot, \cdots 1$ & $\cdot, r \wedge$ & $r$. \\
\hline$\cdot, \cdot \varepsilon$ & $\cdot, r_{1}$ & 91 & $\cdot, Y_{1}$ & $\cdot, 1 \mathrm{~V}$ & $r r$ \\
\hline$\cdot, \cdot \varepsilon$ & $\cdot, Y_{1}$ & $9 r$ & $\cdot, \cdot r$ & $\cdot, Y \varepsilon$ & $r \varepsilon$ \\
\hline$\cdot, \cdots$ & $\cdot, 7$ & 94 & $\cdot, \cdot r$ & $\cdot, r \leq$ & ro \\
\hline
\end{tabular}

ومن خلال ما ذكر آنفاً يتبين أن الفقرات المستبعدة من طريقتي القوة التمييزية للفقرات ،والاتساق الداخلي كانت كما مبينة في الجدول (^) ، اذ استبعد في القوة التميزية (9 () فقرة ،واستبعد في الاتساق الداخلي (r) فقرات، و بذلك يكون المتبقي (1) فقرة ـ 


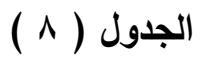

الفقرات المستبعدة بطريقتي التمييز والاتساق الداخلي

\begin{tabular}{|c|c|c|c|}
\hline عدد الفقرات & الفقرات المستبعدة & البعد البد & ت \\
\hline 7 & $r$ ، 0 ، $\varepsilon_{6} r$, $r_{6}$ & التفاؤل & 1 \\
\hline 1 & $\wedge$ & الامل & r \\
\hline 1 & $r$. & الصلابة & $r$ \\
\hline$\varepsilon$ & $r V$ ، $Y O$ ، $r \leq 6 r r$ & المرونة & $\varepsilon$ \\
\hline$r$ & ו & تقدير الذات & ○ \\
\hline$r$ & $\varepsilon \mu_{6} \leqslant, \mu_{\Lambda}$ & الطلاقة & 9 \\
\hline 1 & $\varepsilon \wedge$ & فاعلية الذات & $v$ \\
\hline$r$ & OV ، OO ، Or & الارادة & $\wedge$ \\
\hline - & . & المثابرة & 9 \\
\hline rr & \multicolumn{3}{|c|}{ المجموع } \\
\hline
\end{tabular}

r_r ז الأسس العلمية للمقاييس

r 1_r

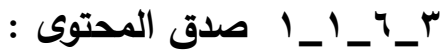

قام الباحثان بالتحقق من هذا النوع من الصدق وذلك عندما عرضت فقرات المقاييس على

مجموعة من المتخصصين لتقويمها ،وللحكم على صلاحية كل فقرة كما مبين في الملحق( (1) ويمثل الملحق الفترات التي تمت صياغتها لكل سمة من السمات الايجابية للشخصية

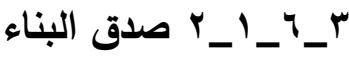

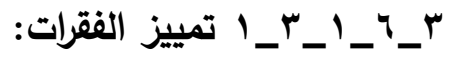

يعتمد هذا الأسلوب على التمييز بين الأفراد الذين يمتلكون السمة والذين لا يمتلكونها وهذه

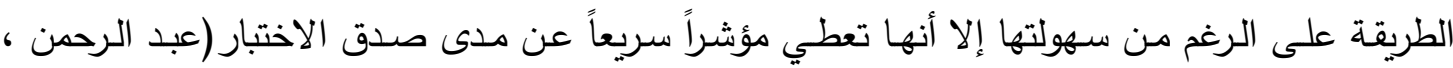

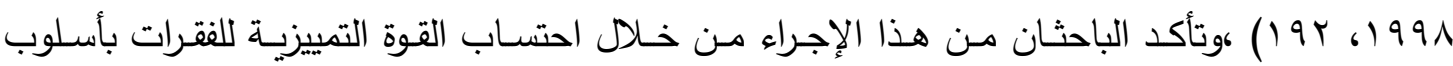

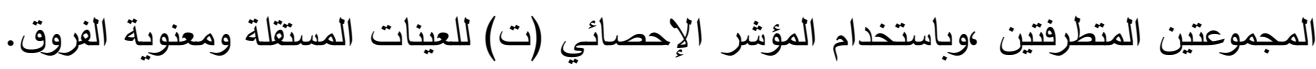

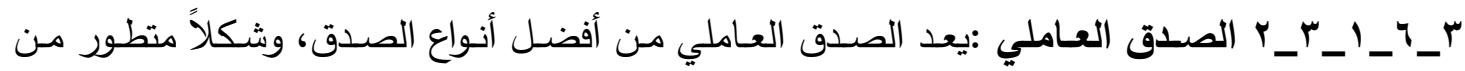

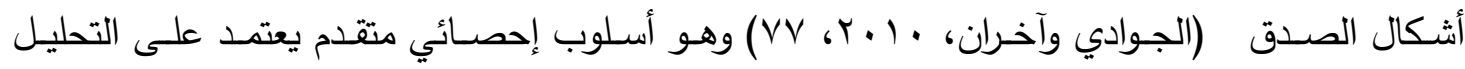

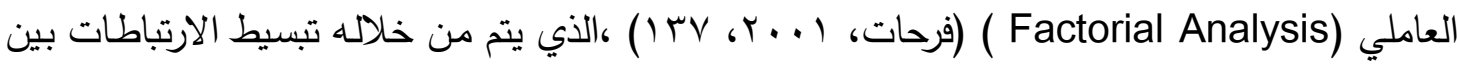

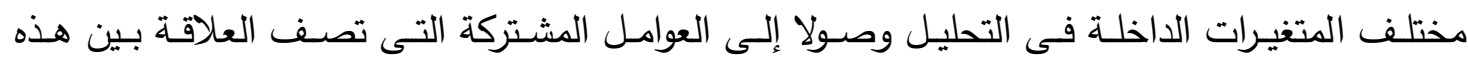

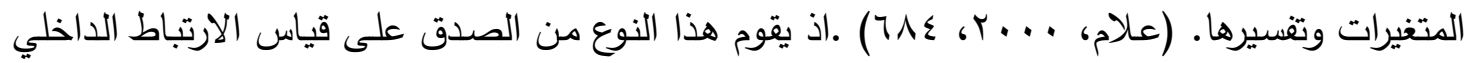

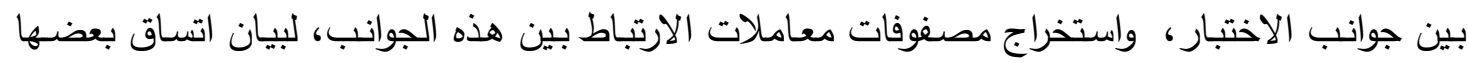


مع البعض الآخر، وكلما كانت نسبة الاتساق عالية، كان معامل الصدق عاليا، وكان الاختبار صـادقا.

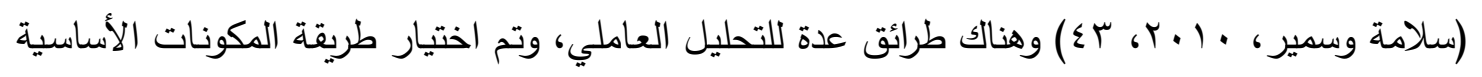

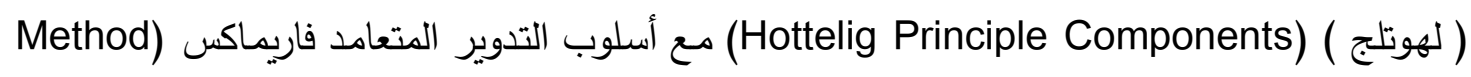
لكايزير ((Varmax Rotation) دقيقة، وكذلك فإن كل عامل يستخرج أقصى كمية من التباين (أي أن مجموع مربعات تشبعات العامل تصل إلى أقصى درجة بالنسبة لكل عامل) ،وتؤدى إلى أقل قدر مدكن من البواقي، كما أن المصفوفة

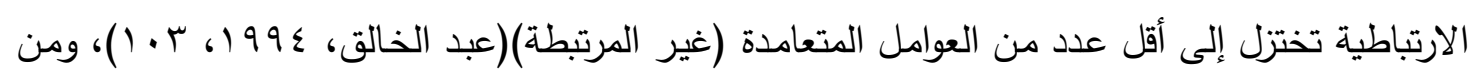

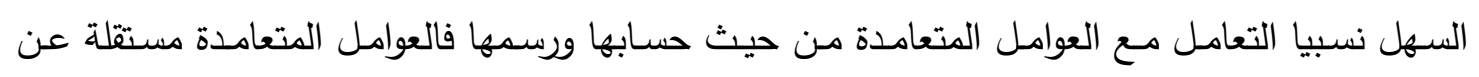

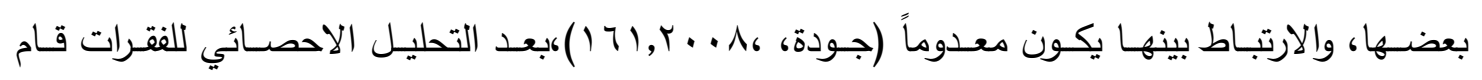

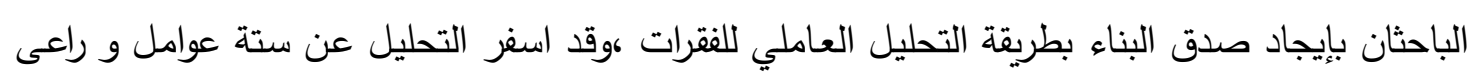
الباحثان في تفسير العوامل و تحديد هويتها عبر الشروط الآتية:

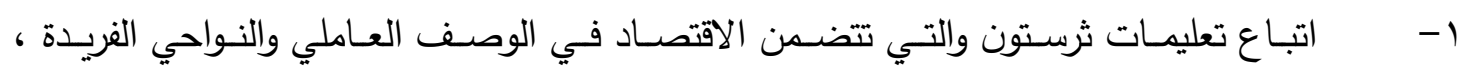

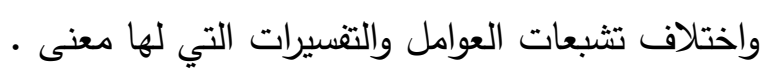
ץ- اتباع تعليمات كاتل ( cattle ) والتي تتضمن تقبل العوامل التي تتفق مـع الحقائق ( الاكلينيكية ) المعروفة ، والعوامل المستخلصـة في دراسـات سـابقة ، التوقعات السيكولوجية العامـة للتوزيـع العامليـة

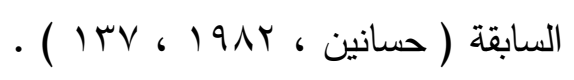

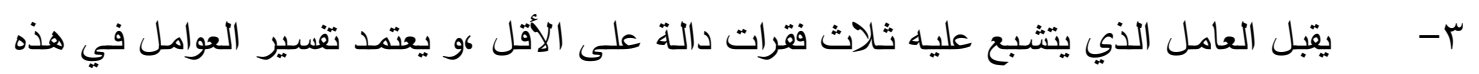

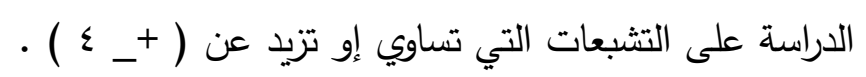

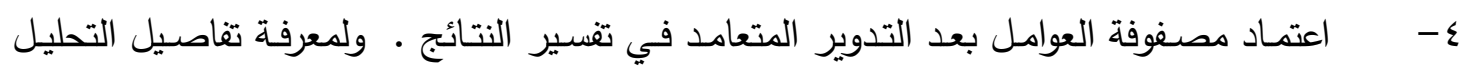
الذي تم تلخيصه في الجدول الآتي :

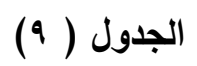

تثبعات الفقرات على العوامل المقبولة للمقياس

\begin{tabular}{|c|c|c|c|c|c|c|}
\hline العامل 7 & العامل • & العامل \& & العامل r & العاملץ & العامل & قم الفقرة \\
\hline & & & & & -, $9 \leq$ & 19 \\
\hline & & & & & $\cdot, \wedge \wedge$ & 11 \\
\hline & & & & & $\cdot, \wedge \varepsilon$ & YY \\
\hline & & & & & $\cdot, \lambda \mu$ & 10 \\
\hline & & & & & $\cdot, v r$ & rI \\
\hline & & & & & $\cdot, 7 \leqslant$ & $1 \varepsilon$ \\
\hline & & & & & $\cdot, \leqslant V$ & rq \\
\hline & & & & & $\cdot, \mathrm{VV}$ & 17 \\
\hline & & & & $\cdot, \Lambda r$ & & 09 \\
\hline & & & & $\cdot, \vee \vee q$ & & 71 \\
\hline
\end{tabular}




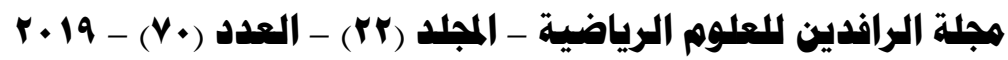

السمات الايجابية للثخصية للاعبين المعاقين في بعض الإلية الالعاب الفرقية بالعراق

\begin{tabular}{|c|c|c|c|c|c|c|}
\hline & & & & - , vo & & 0 . \\
\hline & & & & 0, & & 4 \\
\hline & & & & $\cdot, 7$ & & 7. \\
\hline & & & & $\cdot, 09$ & & $\varepsilon 7$ \\
\hline & & & & $\cdot, 0 \wedge$ & & $\varepsilon \varepsilon$ \\
\hline & & & & $\cdot, O r$ & & $\leqslant 0$ \\
\hline & & & & $\cdot, \leqslant \Lambda$ & & $\varepsilon V$ \\
\hline & & & & $\cdot, \leqslant \wedge$ & & $\varepsilon q$ \\
\hline & & & & 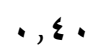 & & $\Delta \wedge$ \\
\hline & & & & & & 1. \\
\hline & & & $\cdot, \wedge \vee$ & & & $r \wedge$ \\
\hline & & & $\cdot, V V$ & & & $r$. \\
\hline & & & $\cdot, 7$ & & & rq \\
\hline & & & - , $\leqslant Y$ & & & r \\
\hline & & & & & & iv \\
\hline & & & & & & ro \\
\hline & & $\cdot, 7 V$ & & & & 9 \\
\hline & & - & & & & V \\
\hline & & - , Tr & & & $\cdot, \varepsilon \Gamma$ & 14 \\
\hline & & $\cdot, \otimes \wedge$ & & & & Ir \\
\hline & & $\cdot, \leq \leqslant$ & & & & 11 \\
\hline & $\cdot, V$. & & & & & $r v$ \\
\hline &., 79 & & & & & $\varepsilon r$ \\
\hline & $\cdot 7$ & & & & & q \\
\hline & $\cdot, \leqslant 9$ & & & & & $\leqslant 1$ \\
\hline & $\cdot, \leqslant \mu$ & & & & & $\varepsilon r$ \\
\hline & & & & & & rq \\
\hline$\cdot, 0 \wedge$ & & & & & & 01 \\
\hline$\cdot, \leq 9$ & & & & & & 07 \\
\hline$\cdot, \leq \leqslant$ & & & & & & or \\
\hline -,$\leqslant Y$ & & & & & & $0\}$ \\
\hline
\end{tabular}


تسمية العوامل : العامل الأول : (20)

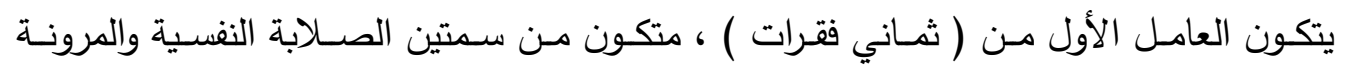

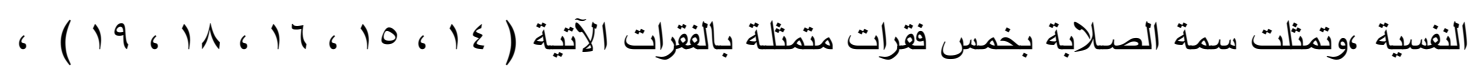

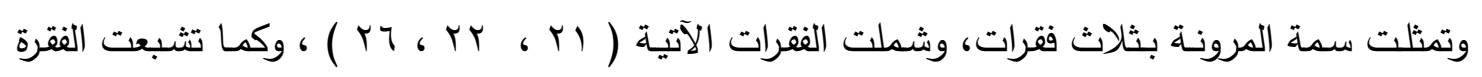

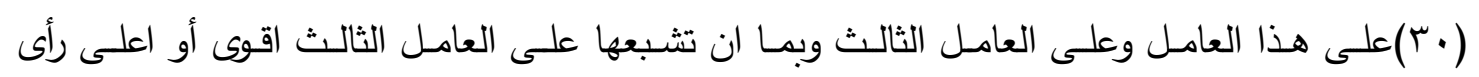

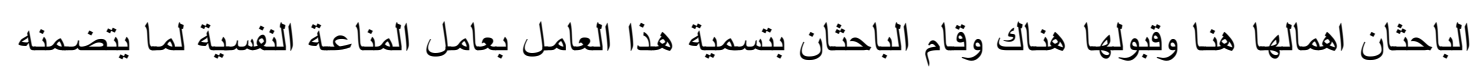

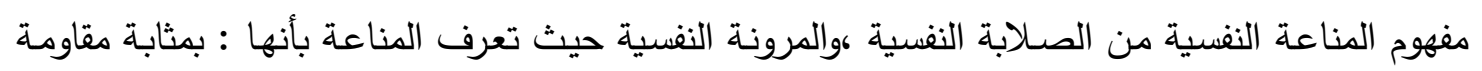

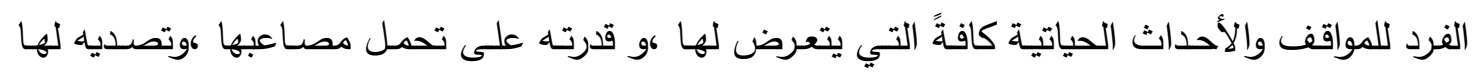

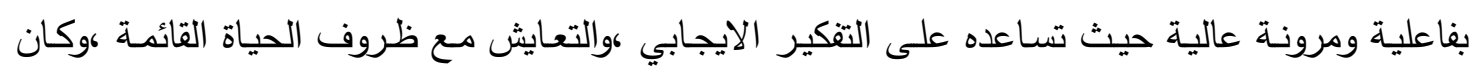

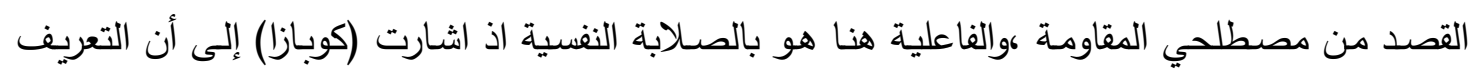

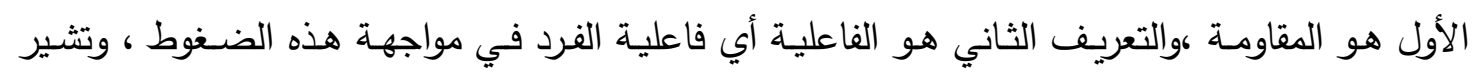

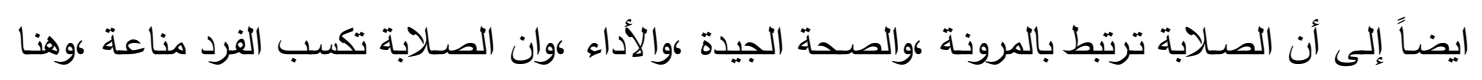

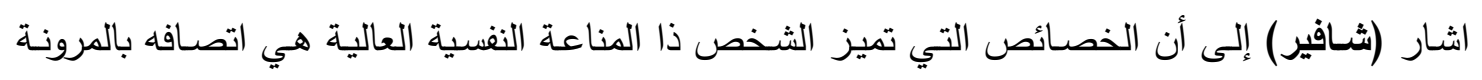

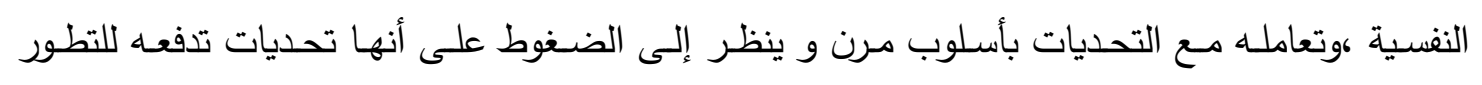

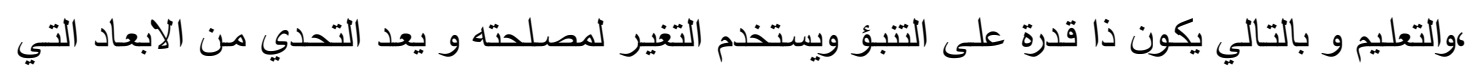

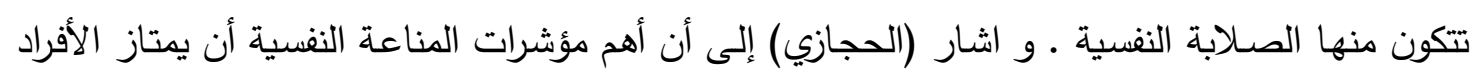

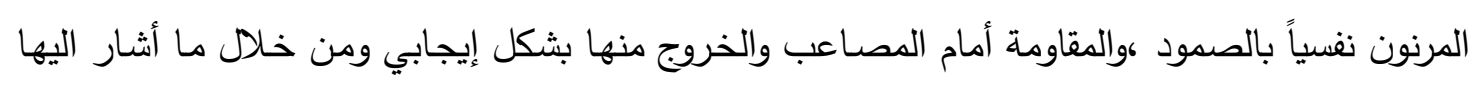
الباحثان استطاعا تسمية هذا العامل بالمناعة النفسية.

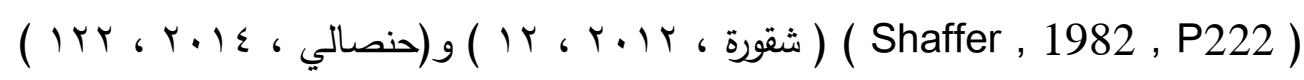

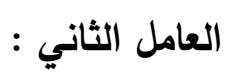

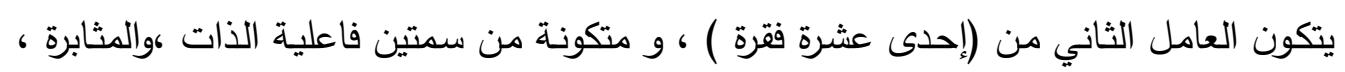

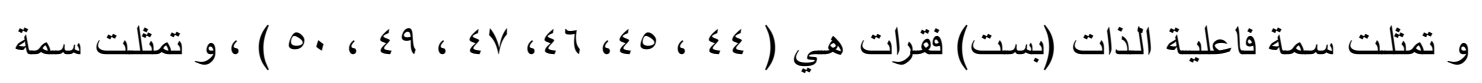

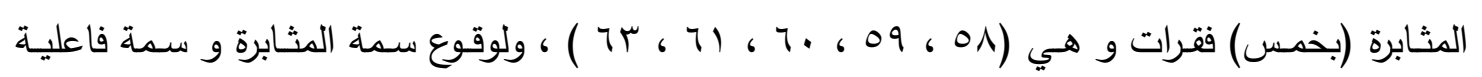

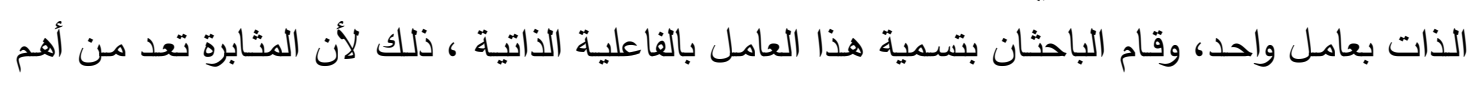

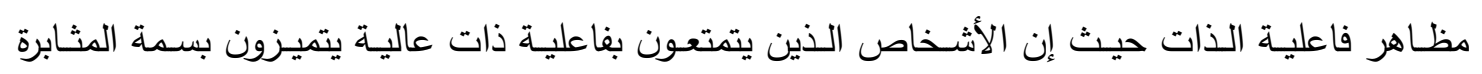

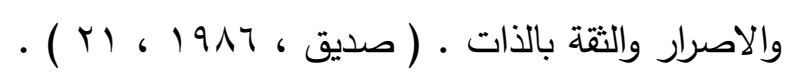
العامل الثالث :

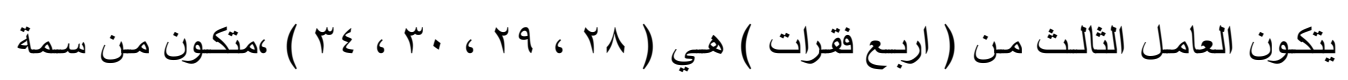

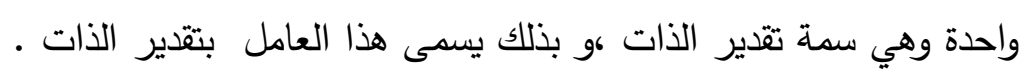


يتكون العامل الرابع من ( خمس فقرات ) ، متكون من سمتين التقاؤل و الأمل ، و تمثلت سمة

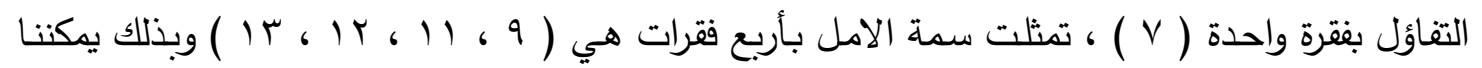
ان نطلق على هذا العامل بالتفكير الايجابي ،وعرفه (شقورة )بأنه التفاؤل و الاحساس بالقدرة على النجاح ، كمـا وأشـار (الفقي) إلى ان الخصـائص التي يتميز بها الافراد ذوي التفكير الايجابي ،و الثخصية

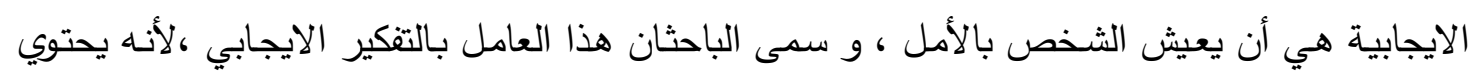

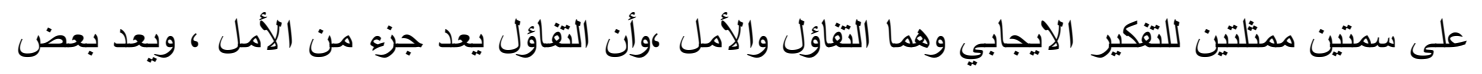

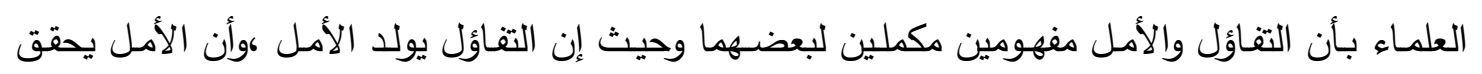
التفاؤل ـ فضلاً عن إن بعض نظريات علم النفس الايجابي في كل من التفاؤل و الأمل تدرجهما اساساً

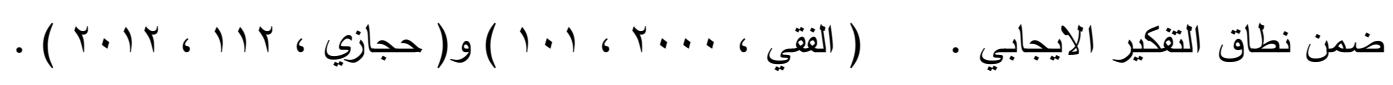
العامل الخامس : nesi

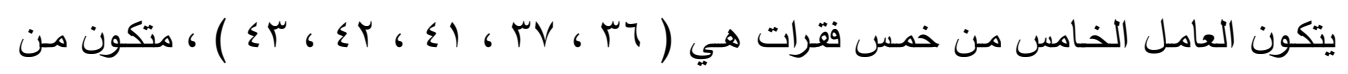
سمة واحد هي الطلاقة وبذلك يسمى هذا العامل بالطلاقة .

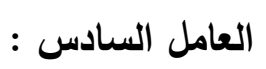

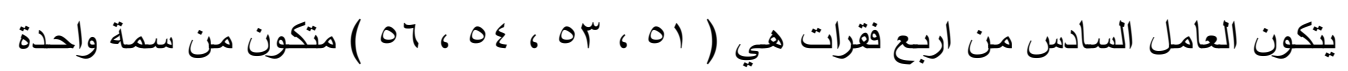
وهي الإرادة و بذلك يسمى هذا العامل بالإرادة . : الثبات يعني الثبات " الدقة في تقدير العلامة الحقيقية للفرد على السمة التي يقيسها الاختبار " (عودة

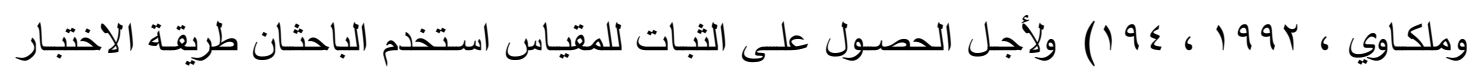
وإعادة الاختبار . : الاختبار وإعادة تطبيقه يثير الثبات بهذه الطريقة إلى اتساق الدرجات المستخرجة من استجابات الأفراد أنفسهم، عندما

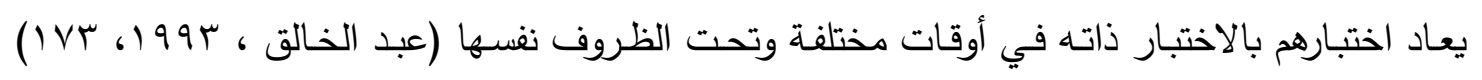
وتتمثل معطيات هذه الطريقة بمعامل الاستقرار بوجود فاصل زمني • وقد قام الباحثان بحساب درجة الثبات للمقياس بطريقة تطبيق الاختبار وإعادة تطبيقه وقد طبقت المقاييس على عينة قوامها (· ب) لاعباً ، يمثلون كرة السلة ،والكرة الطائرة وبفاصل زمني قدرة (1) يوما. جرى التطبيق الأول للثبات للمدة من

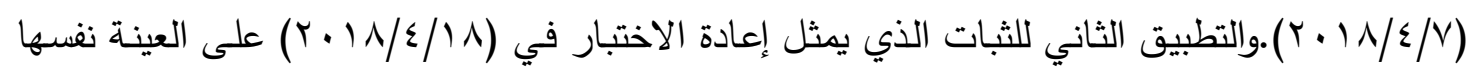
مع توحيد الظروف للتطبيقين قدر الإمكان ، تلا ذلك معالجة البيانات إحصائيا من خلال معامل الارتباط البسيط وقد بلغت قيمة معامل الثبات (برد, •). 


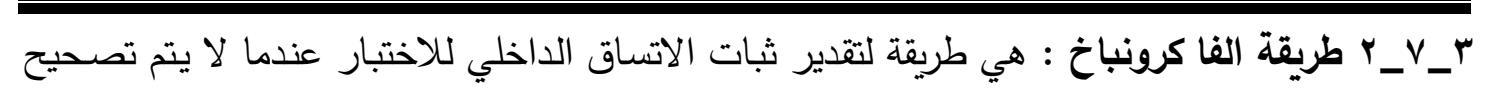

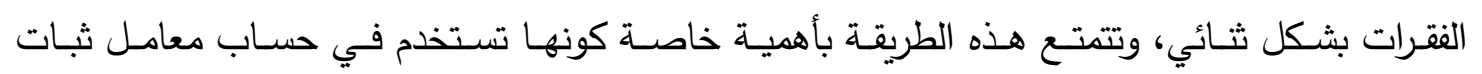

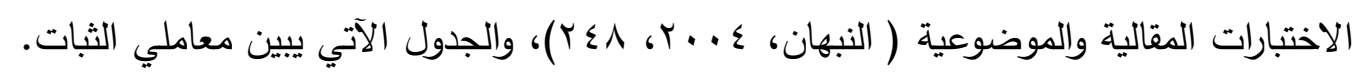

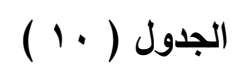

الثبات بطريقتي الاختبار و إعادة الاختبار والفا كرونباخ ، الخاخ

\begin{tabular}{|c|c|}
\hline قيمة معامل الثبات & طريقة الثبات \\
\hline$\cdot, \wedge r$ & الاختبار - اعادة الاختبار \\
\hline$\cdot, \wedge 0$ & الفاكرونباخ \\
\hline
\end{tabular}

ومن الجدول(· (1) يستدل الباحثان على ان المقياس يتمتع بثبات عالي ويعكس الجودة العالية له. ب-1 التجربة الاستطلاعية الثانية بعد التحقق من الخصائص السيكومترية للمقياس عمد الباحثان إلى إجراء التجربة الاستطلاعية الثانية بهدف التعرف على الوقت المستغرق للإجابة عن فقرات المقياس على عينة من ( ه ) لاعبين ، اختيروا

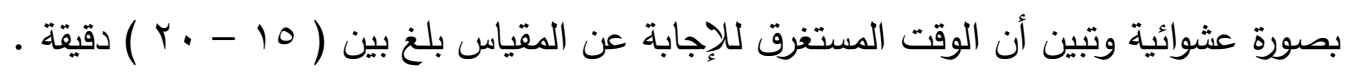

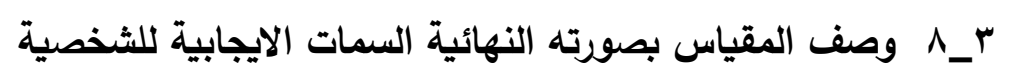
يتكون المقياس بصورته النهائية من (ستة) ابعاد ،و تمثل البعد الاول بالمناعة النفسية متمثلة بالفقرات

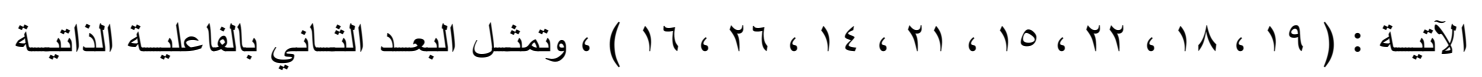

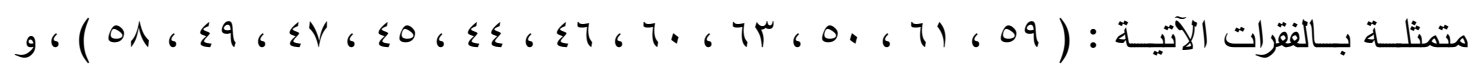

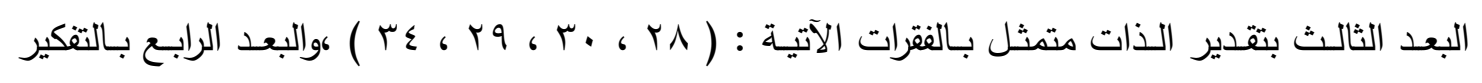

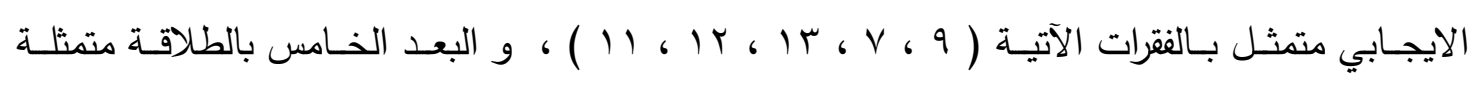

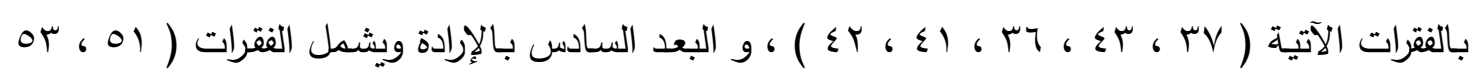

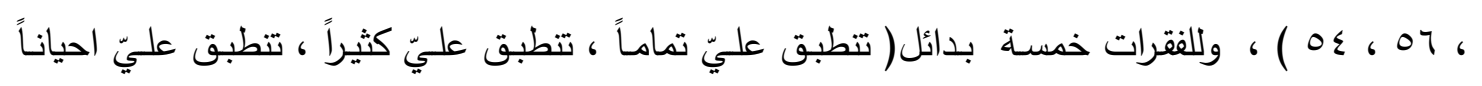
،تنطبق عليّ قليلاً ، لا تتطبق عليّ اطلاقاً) ، تعطى الدرجات للمقياس (

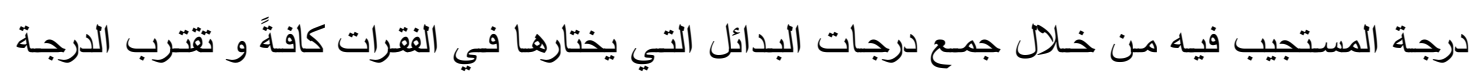

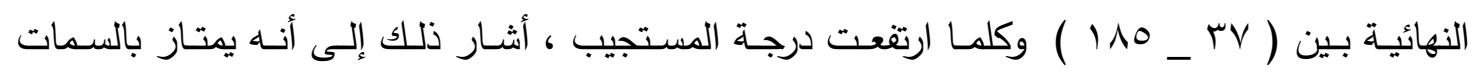

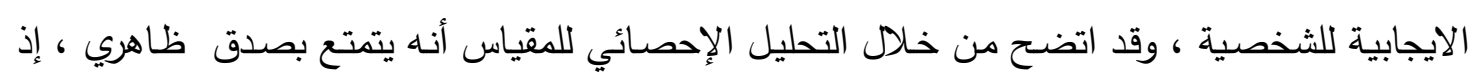

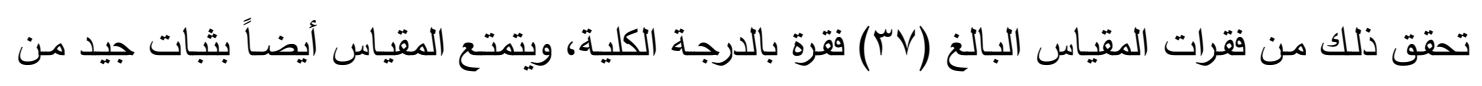

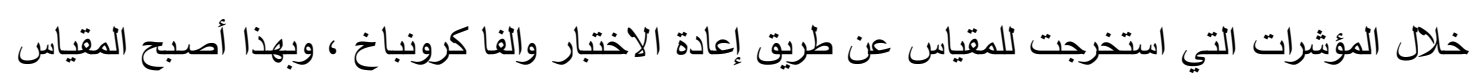
جاهزاً للتطبيق. r_a التطبيق النهائي: بعد استكمال المستلزمات العلمية المطلوبة كافة لإعداد وتهيئة مقياس السمات

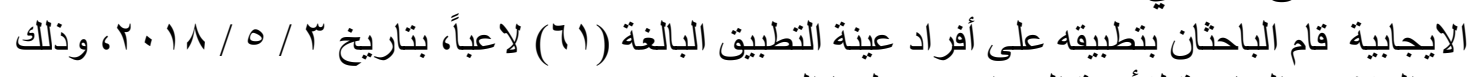

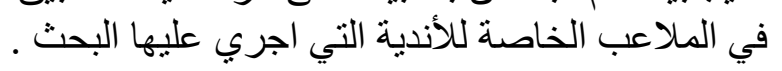

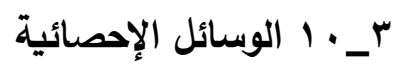
- الوسط الحسابي - الانحراف المعياري - النسبة المئوية - التحليل العاملي 


\section{- معامل ارتباط بيرسون - الاختبار التائي لعينتين مستقلتين \\ r- عرض النتائج ومناقشتها}

r-1 بناء مقياس السمات الايجابية في الثخصية للاعبي المعاقين لبعض الألعاب الفرقية بالعرلق تحقق الهذف الاول في أثناء بناء المقياس الذي استوفى الشروط اللازمة لهذا النوع من المقاييس النفسية ،وكما موضح بشكل تفصيلي في الفصل الثالث من هذه الدراسة، ويعد هذا المقياس أحد الأدوات المهمة والمكملة لتحقيق أهداف البحث الأخرى. ويشير (حسانين ، 1990) أن الاختبارات التي يتم بناؤها وتقنينها على عينات تمثل مجتمع المستفيدين، تعد أصلح من غيرها التي تم بناؤها وتقنينها على عينات تمثل مجتمعا آخر مهما بلغت درجة التشابه بين المجتمعين.

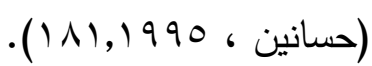
r-r التعرف على الوصف الأوساط الحسابية والانحرافات المعيارية والفروق لجميع متغيرات البحث

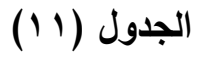

المتوسط الحسابي والانحراف المعياري وقيمة (ت) المحسوبة بين المتوسط الفرضي لمقياس للسمات الايجابية للشخصية وإجابات أفراد عينة البحث ولائه

\begin{tabular}{|c|c|c|c|c|c|}
\hline قيمة الاحتمال & قالمسة ت & الفوضط الفري & الانعراف & الحسابي الوسط & المتغير \\
\hline . & $r Y, \wedge q$ & $Y \varepsilon$ & $r, r \vee \wedge$ & $r \varepsilon, r \vee \wedge$ & المناعة النفسية \\
\hline . & $|\Lambda, \&|$ & $r r$ & $r, 17 V$ & $\{\varepsilon, \cdot Y \mid$ & الفاعلية الذاتية \\
\hline - & r., & Ir & $1,7 \times 9$ & $\mid \wedge, . \Delta 1$ & تقدير الذات \\
\hline - & 0,Vד & 11 & $r, r \wedge q$ & $r \cdot, v q 1$ & التفكير الايجابي \\
\hline - & I I, & 11 & $1, \Lambda \cdot r$ & $r \cdot, \wedge 90$ & الطلاقة \\
\hline . & 1,91 & ir & $7, \varepsilon \mid r$ & $r \Delta, r, \varepsilon$ & الارادة \\
\hline
\end{tabular}

يتبين من الجدول (1) بأنه توجد فروق ذات دلالة معنوية بين المتوسط الفرضي واجابات أفراد عينة البحث بشكل عام على مقياس السمات الايجابية للشخصية (المناعة النفية ،والفاعلية الذاتية ،وتقدير الذات ،والتفكير الايجابي ،والطلاقة النفسية ،والارادة ) وذلك بالاعتماد على معنوية (sig) والبالغة (·) (. لجميع السمات ، إذ تبين بأن قيمها المحسوبة أصغر من قيمة مستوى الدلالة المعنوية (0., •) ولصالح أفراد العينة البحث .ومن خلال نتائج الجداول (1) (1) تبين للباحثين أن لاعبي أفراد عينة البحث يمتلكون

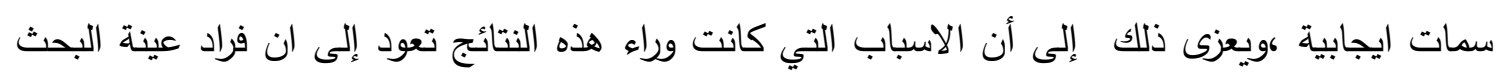
تميزت درجاتهم فوق المتوسط النظري للمقياس في مجمل مجالات البحث ،وعليه فإن الأسباب عدة إنهاب

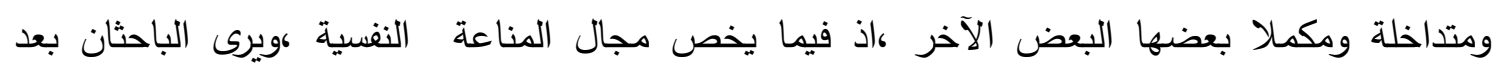
اطلاعها على العديد من المواضيع التي تتاولت موضوع المناعة النفية هذه النتيجة تفسر في ضوء ممارسة الأنشطة الرياضية تعطي فرصاً حقيقة للاعبين المعاقين لتوفير عوامل تحقيق الصحة النفسية ،والمتمثلة بالمشاركة في المنافسات الرياضية المختلفة وما يصاحبها من فعاليات ترفيهية ،تضع اللاعبين في مناخ نفسي يمتثل الاطمئنان والاستقرار النفسي والتفاؤل بحيث ينعكس بدوره على درجة المناعة النفسية 
إذ إن تجاوز الصفات المزاجية السلبية مثل الانفعالية ،و قلة النشاط، والانطوائية، أو تتظيم الصفات بلهيل المزاجية السلبية من خلا الصفات الثخصية المتطورة والسيطرة عليها بصورة إرادية من خلال التدريب فيظهر الفرد الانفعالية متزناً في المواقف الطبيعية ـ (الويس، 1919 ا، • V) ،إذ إن إحدى مفاهيم المناعة

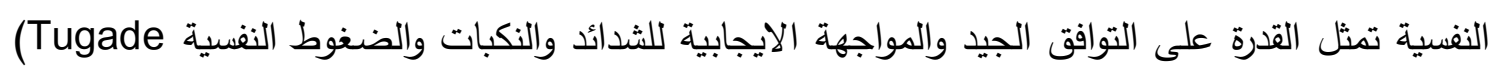
etal,2004,190) الرياضي • أما فيما يخص فاعلية الذات فيرى الباحثان انه يدخل في تكوين الذات للرياضيين بصورة

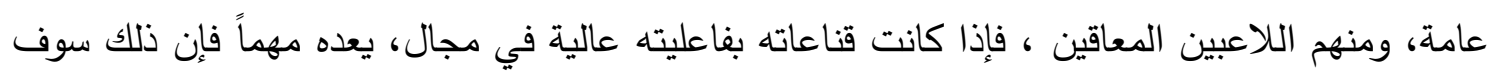
يثكل مفهوماً إيجابياً ،وإن الفاعلية الذاتية الواطئة تؤثر بشكل كبير على تحقيق أي أداء مما يفقده الثعور

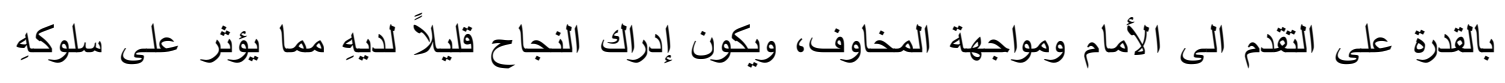
خلال المنافسة والعكس صحيح، ولأن ظروف المباريات تتطلب من اللاعبين أن يبذلوا أقصى ما يمكنهم من قدرات بدنية ،ومهارية ،وخططية ،ونفسية لتمكنه من تحقيق أهدافهم لأنهم يواجهون منافساً غير

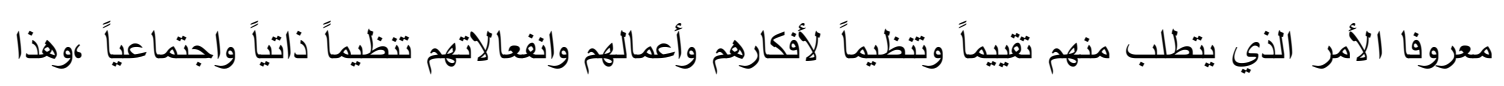

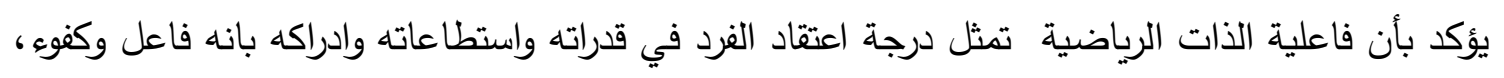
ويستطيع النجاح في اداء سلوك نوعي معين (علاوي، 991 (1)، بvo) .ومن هنا تؤدي فاعلية الذات دوراً مهماً في التأثير على الأداء الرياضي اللاعبين المعاقين ، وان مستوى فاعلية الذات لديهم يمثل العامل الحاسم في انجاز أقصى اداء ممكن، وقد صاغ (بانديورا) فاعلية الذات من خلال تصوره للتغير السلوكي الذي يحدث بوساطة الميكانزم المعرفي لفاعلية الذات، وان مدركاتها تعني "مدى اعتقاد الفرد انه يمكنه ان ينفذ بنجاح سلوكيات مثل الأداء الرياضي، وتحقيق نتيجة مؤكدة مثل النجاح في الرياضة " (محمد،

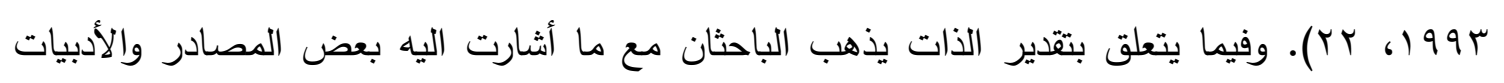
والدراسات النفسية إلى ارتباط الذات بمفاهيم عدة ومنها مفهوم تقدير الذات ، اذ يرى ( Cooper Smith) ، أن تقدير الذات هو ما يعتقده الفرد عن نفسه بأن لديه القدرة والإمكانات والإحساس بالنجاح والقيمة في

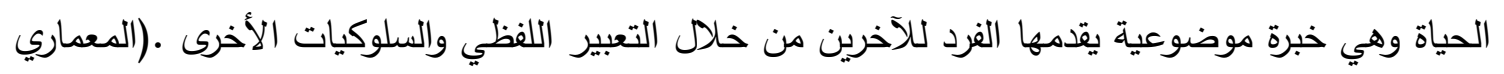

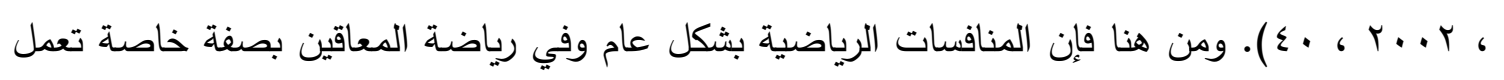
تعزيز الثقة بالنفس كونها افضل بيئة يتم من خلالها اكتساب الرياضي على العنى العديد من السمات الايجابية

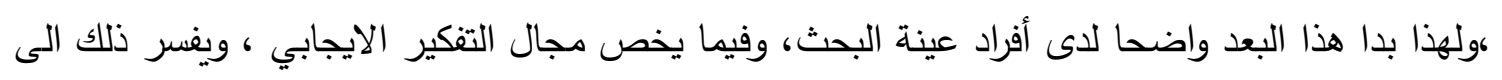

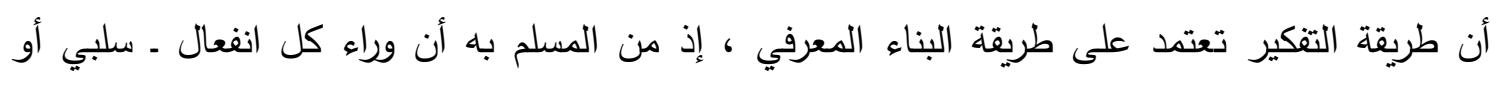

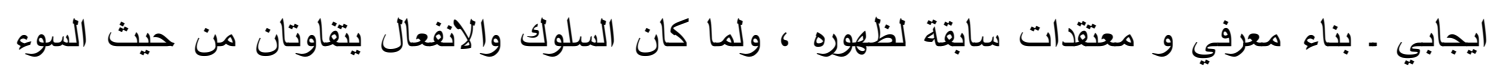

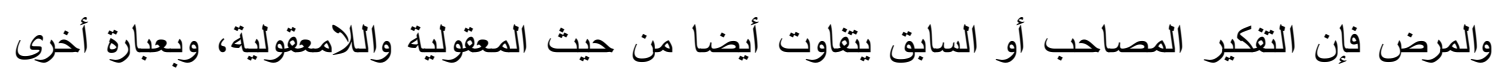
إذا كانت طريقة التفكير عقلية ومنطقية فإن السلوك أو الانفعال سيكون ايجابياً ودافعاً لمزيد من النشاط والبناء، وكانت العكس فإن السلوك والانفعال كليهما سيكونان على درجة مرتفعة من الاضطراب(إبراهيم ، ولئه

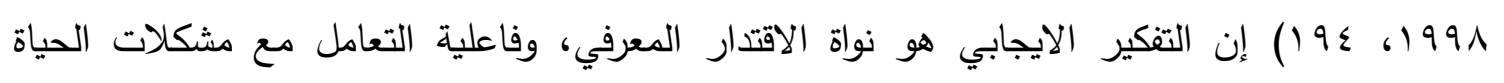

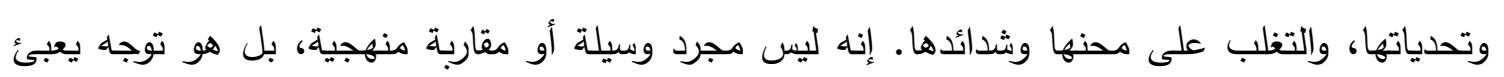




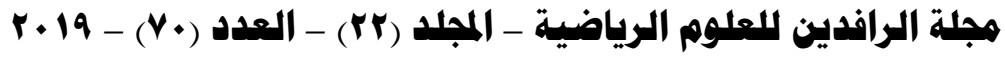

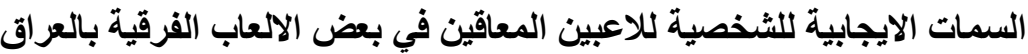

الطاقات ويستخرج الإمكانات الحاضرة منها والكامنة من أجل العمل. كما أن التفكير الإيجابي يشكل

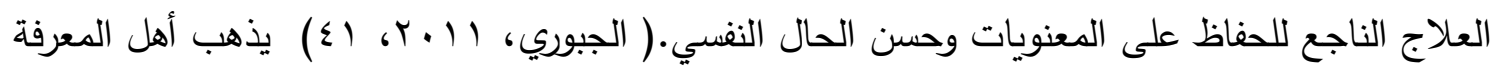
بالتفكير الإيجابي إلا أن التفكير في أمر ما والتركيز عليه هو أحد القوانين الرئيسة في توجيه حياة الإنسان

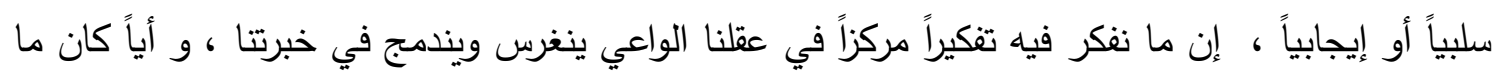
تعتقده فسيتحول إلى حقيقة عندما تمنحه مشاعرك ، وكلما اشتدت قوة اعتقادك ، وارتفعت العاطفة التي تضيفها إليه تعاظم بذلك تأثير اعتقادك على سلوكك وعلى كل شيء يحدث لك ، يظل الأشخاص

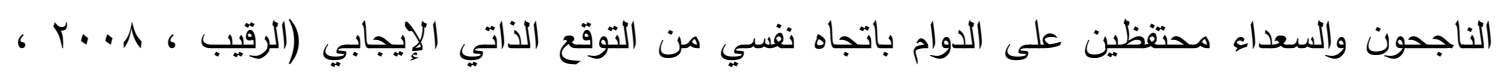
V IV) ويشير الباحثان بأن التفكير الايجابي هو ذلك النوع من التفكير الذي ينسجم مع أهدافنا العامة ،

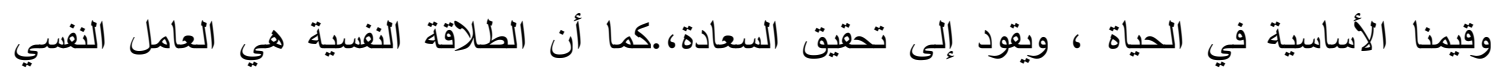
الأساس بوصفها خبرة ذاتية ايجابية تكون على ارتباط وثيق بالأداء المثالي والقهي كما أن أغلب مصادرها

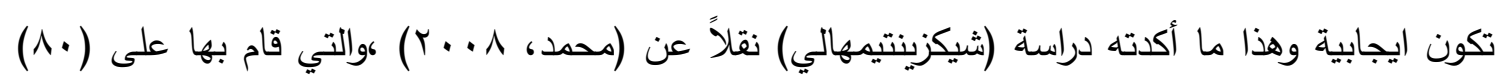
لاعباً امريكياً لدراسة الخصائص النوعية لخبرة الطلاقة النفسية في أنشطة مختلفة ووجد أن خبرة الطلاقة ترتبط بالعديد من الخصائص الايجابية جاء في مقدمتها التحدي، فضلاً عن الاستماع والمهارة. كما أن الطلاقة النفية تأتي نتيجة لتغيرات طويلة المدى او تكيفات في طريقة الفعل ،فضلاً عن المتغيرات البدنية والمهارية التي تتحقق بالتدريب والخبرات الخاصة بالنجاح والفشل، والتي تكتسب بالممارسة والمنافسة فهذه

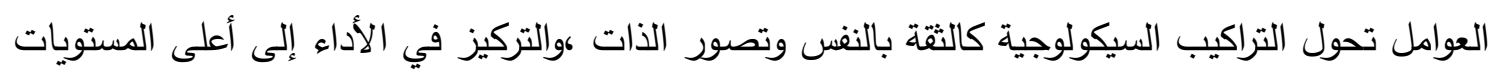

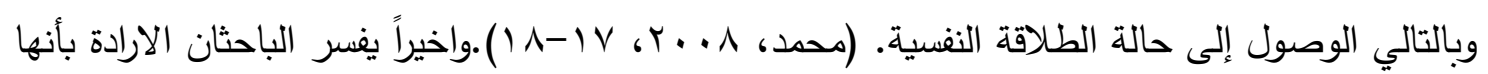
ذلك النشاط النفسي الذي يوجه إلى التحكم في أعمال وأفكار وانفعالات الفرد لغرض الوصول إلى الاهداف التهي المطلوبة مع التغلب على مختلف الصعوبات التي تواجه الفرد في طريق الوصول إلى الهدف و يجب على إلى الرياضي أن يتدرب دائما على الصعوبات وتجاوز العقبات والمصاعب الداخلية والخارجية ، لأن قوة الارادة لا يمكن أن تقوى إلا عن طريق بذل الجها المتواصل ،وإذا أراد الرياضي أن يتغلب على المصاعب واعب عليه ان يعرف لماذا يفعل ذلك وليس غيره وعليه ان يتعلم كيف يحكم بصدق على تصرفاته. ( محمود

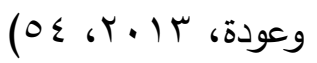

$$
\text { ع - الاستنتاجات والتوصيات }
$$

ع - ا الاستنتاجات : استنتج الباحثان ما يأتي: ا. ـ اثبت مقياس السمات الايجابية للاعبي المعاقين لبعض الالعاب الفرقية في العراق فاعلية عالية كوذلك عن طريق التوصل إلى بنائه وبمواصفات علمية دقيقة . Y. يمتلك لاعبو المعاقين لبعض الالعاب الفرقية في العراق بشكل عام درجات عالية تفوق المتوسط الفرضي في مقياس السمات الايجابية في الثخصية . ع - r التوصيات : أوصى الباحثان بما يأتي :

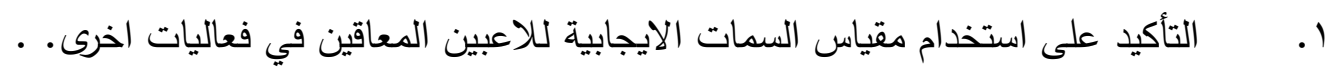




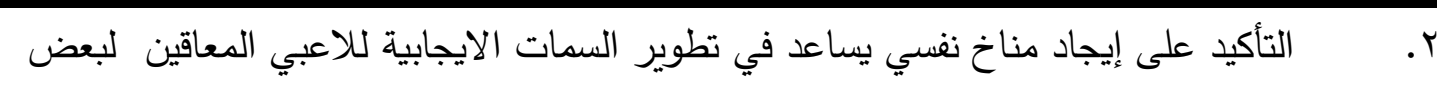
الالعاب الفرقية في العراق. - المصادر -

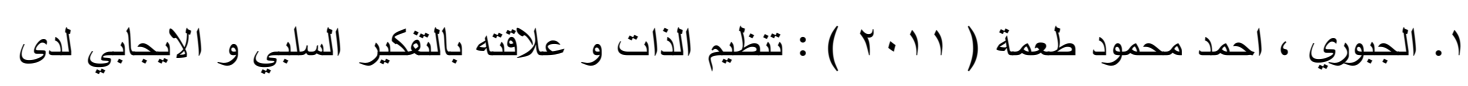
طلبة المرحلة الاعدادية ، رسالة ماجستير ، جامعة تكريت ، كلية التربية .

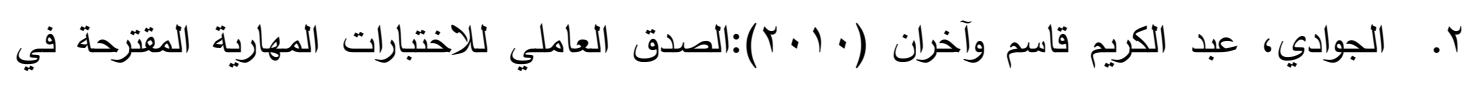
اختيار الطلاب المتقدمين للقبول في كلية التربية الرياضية، مجلة الرافدين لعلوم الرياضية، جامعة الموصل، المجلد 71 (، العددبه .

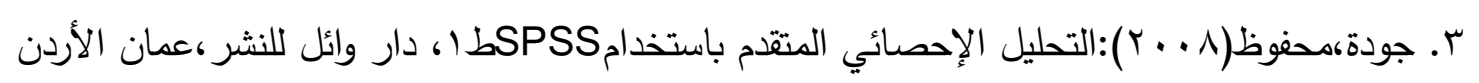
ع. حجازي ، مصطفى ( r ـ r ) : اطلاقات طاقات الحياة ( قراءات في علم النفس الايجابي ، التتور للطباعة و النشر ، مؤسسة يمو برس للطباعة و التجارة ، لبنان • 0. حسانين، محمد صبحي (1990): التقويم والقياس في التربية الرياضية ، الجزء الاول،طس، دار الفكر للطباعة والنشر والتوزيع، عمان.

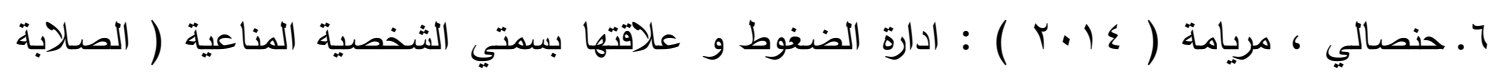
النفسية و التوكيدية ) في ضوء الذكاء الانفعالي ، اطروحة دكتوراه ، جامعة محمد خيضر - بسكرة كلية العلوم الانسانية و الاجتماعية .

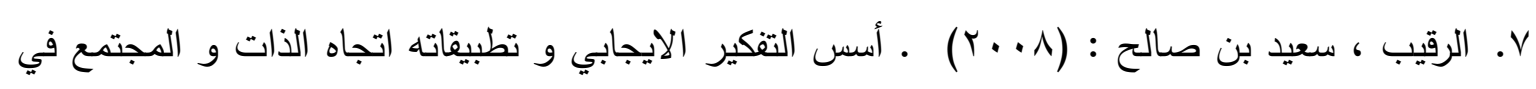
ضوء السنة النبوية ـ بحث غير منشور كلية التربية جامعة الباحة . ^. زهران،حامد عبدالسلام(997 (19) : الصحة النفسية و العلاج النفسي ، طب ، عالم الكتب ، القاهرة ،

\section{مصر}

9. سلامة، عبد الحافظ، وسمير، أبو مغلي ( • • ب):القياس والتشخيص في التربية الخاصة، دار اليازوري العلمية للنشر والتوزيع ،عمان، الأردن.

• (.شقورة ، يحيى عمر شعبان ( T Y r ) ) المرونة النفية و علاقتها بالرضا عن الحياة لاى طلبة الجامعات الفلسطينية بمحافظات غزة ، رسالة ماجستير ، جامعة الازهر ، غزة ، كلية التربية علم النفس. ا(.صديق ، عمر الفاروق ( 1917 ) : الفاعلية و علاقتها بالتوافق النفسي لدى قطاعات من الثباب المصري ، رسالة ماجستير ، كلية التربية ، جامعة عين شمس ، القاهرة ، مصر • r (.طه ، حسين ياسين و علي خان ( • 199 ) ) : علم النفس العام ، بغداد ، الدار الوطنية. r ا .عبدالخالق ، احمد محمد (ب991 (1) : قياس الثخصية ، جامعة الكويت ، مجلس النشر العلمي • ع ( .عبدالرحمن سعد ( 1991 ) : القياس النفسي ، ط1 ، الكويت ، مكتب الفلاح . 
1 . عثمان ، فاروق السيد ( ( . ب ) : القلق و ادارة الضغوط النفية ، طا ، دار الفكر العربي ، القاهرة . 1 ا.علام ، صلاح الدين محمود ( . . . r) : القياس و التقويم التربوي و النفسي _ اساسياته و تطبيقاته و توجهاته المعاصرة ، دار الفكر العربي ، القاهرة .

V V .علاوي، محمد حسن (991 (19) : مدخل علم النفس الرياضي، طا، دار المعارف للطباعة والنشر، القاهرة 11.عوده ، احمد سليمان و ملكاوي ، فتحي حسين (r99 1) : اساسيات البحث العلمي في التربية و العلوم الانسانية ، طا ، مكتبة الكتاب للتوزيع ، الاردن .

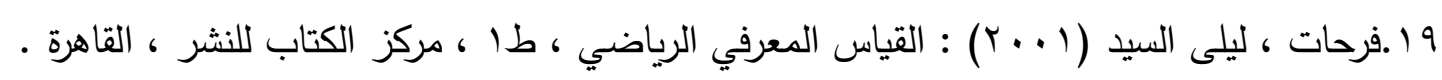

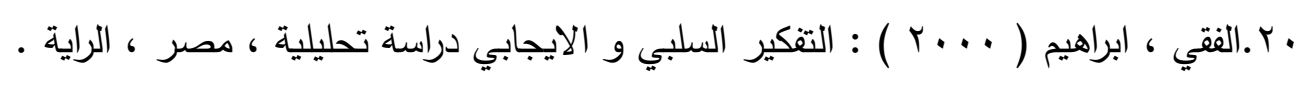

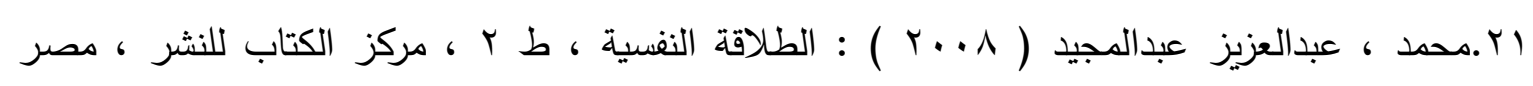

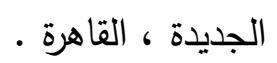

r .محمد، صدقي نور الدين (ب991) : اختبار الطرق المستخدمة بواسطة مدربي الملاكمة لزيادة فاعلية الذات لدى الملاكمين، مجلة اسيوط لعلوم وفنون التربية الرياضية، العدد (ץ)، الجزء (ץ) •

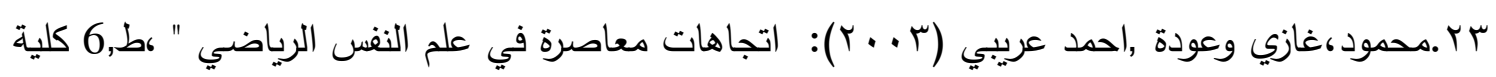
التربية الرياضية ,الجامعة المستصرية ,مكتب المجتمع العربي للطباعة والنشر والتوزيع عمان ,الاردن.

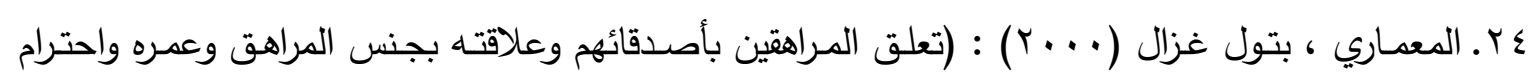

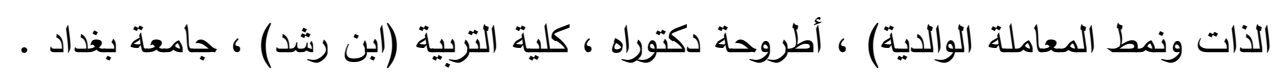

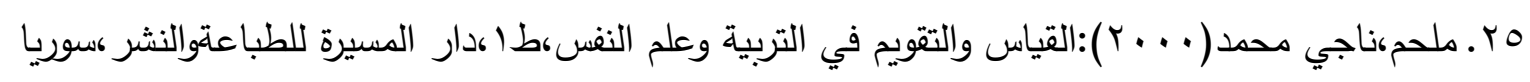

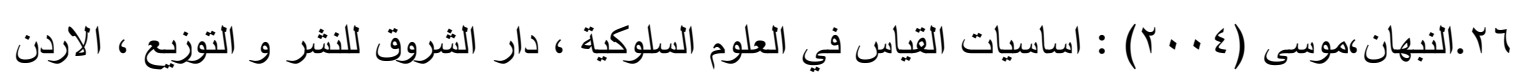
V. الهنداوي ، علي و الزغلول ، عماد ( r . . T ) : مبادئ اساسية في علم النفس ، مكتبة الفلاح للنشر و التوزيع ، العين ، دار جنين للنشر و التوزيع ، عمان · ل

28.Shaffer, Marten ( 1982 ), life after stress . new York, plenumpress .

29. Tugade , M , , et.al ( 2004 ) Psychological Resilience And Positive Emotional Granularity :Examining The Benefits Of Positive ' Journal Of Personality . 
(1) (1) (1) (1)

يبين أسماء السادة الخبراء المتخصصين الذين استعان الباحثان بآرائهم في بعض إجراءات البحث

\begin{tabular}{|c|c|c|c|}
\hline 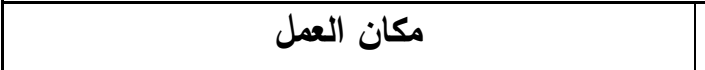 & التخصص & أسماء السادة الخبراء & $ت$ \\
\hline التربية البلنية و علوم الرياضة / جامعة الموصل & قياس وتقويم & أ.د ثيلام يونس علاوي & 1 \\
\hline التربية البذنية وعلوم الرياضة / جامعة الموصل & علم النفس الرياضي & أ.د ناظم شاكر الوتار & $r$ \\
\hline لتربية البدنية و علوم الرياضة / جامعة صلاح الدين & علم النفس الرياضي & |أ.د عظيمة عباس السلطاني & $r$ \\
\hline التربية البذنية و علوم الرياضة / جامعة الموصل & علم النفس الرياضي & أ.د عصام محمد عبدالرضا & $\varepsilon$ \\
\hline التربية البدنية و علوم الرياضة / جامعة كركوك & علم النفس الرياضي & أ. أد مها صبري & $\bullet$ \\
\hline قسم علم النفس التربوي / كلية التربية / جامعة & علم النفس التربوي & أ.م. د د سمير يونس & 7 \\
\hline قسم التربية البدنية و علوم الرياضة / كلية التربية & علم النفس الرياضي & أ.م. د نبراس يونس المراد & $v$ \\
\hline كلية التربية البذنية و علوم الرياضة / جامعة & علم النفس الرياضي & أ.م. د نغم محمود العبيدي & $\wedge$ \\
\hline قسم التربية البدنية و علوم الرياضة / كلية التربية الاساسية / جامعل الموصل & علم النفس الرياضي & 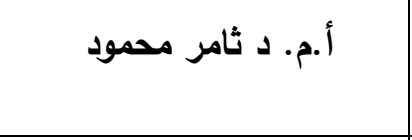 & 9 \\
\hline كلية التربية البدنية و علوم الرياضة / جامعة & علم النفس الرياضي & 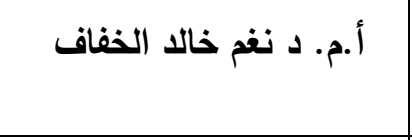 & $1 \cdot$ \\
\hline كلية التربية البدنية و علوم الرياضة / جامعة صلاح & علم النفس الرياضي & 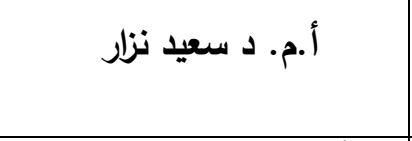 & 11 \\
\hline كلية التربية البدنية و علوم الرياضة / جامعة بغداد & علم النفس الرياضي & أ.م. د ماهر عبدالاله & $1 \mathrm{r}$ \\
\hline كلية التربية البدنية و علوم الرياضة / جامعة & علم النفس الرياضي & أ.م. د افع ادريس & 14 \\
\hline كلية التربية البدنية و علوم الرياضة / جامعة & علم النفس الرياضي & 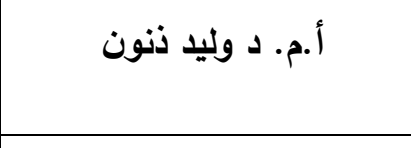 & $1 \varepsilon$ \\
\hline كلية التربية البدنية و علوم الرياضة / جامعة & علم النفس الرياضي & 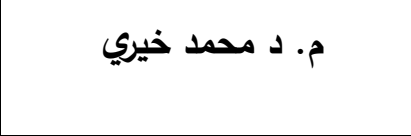 & 10 \\
\hline
\end{tabular}

